\title{
Las labiadas (Lamiaceae) de Guinea Ecuatorial
}

\author{
por \\ R. Morales \\ Real Jardín Botánico, CSIC, Plaza de Murillo 2, E-28014 Madrid, España. morales@rjb.csic.es
}

\begin{abstract}
Resumen
Morales, R. 2011. Las labiadas (Lamiaceae) de Guinea Ecuatorial. Anales Jard. Bot. Madrid 68(2): 199-223.

Se estudian e identifican 223 colecciones de plantas vasculares que corresponden a 14 géneros y 28 especies pertenecientes a la familia Lamiaceae procedentes de las islas de Bioko, Annobón y Río Muni (Guinea Ecuatorial continental). Se incluye una clave de géneros y en cada género, si ha lugar, clave de especies. Se citan de cada especie su basiónimo y material tipo, se incluyen una breve descripción y números cromosomáticos, área de distribución y usos populares conocidos. Se aportan fotografías de pliegos y mapas de distribución. Se discuten aspectos biogeográficos dentro de la distribución genérica y específica en el área estudiada. Se propone la combinación Calaminta pseudosimensis (Brenan) R. Morales, comb. nov.
\end{abstract}

Palabras clave: Lamiaceae, Guinea Ecuatorial, Bioko, Río Muni, Annobón, distribución, biogeografía.

\section{Introducción}

Guinea Ecuatorial es un pequeño país africano, el único hispano, resultado de la fusión de dos antiguas provincias españolas en África ecuatorial, la isla de Fernando Poo y el territorio continental de Río Muni. Desde 1968 es un estado independiente y la isla ha pasado a llamarse Bioko. Además pertenece a dicho país la pequeña isla de Annobón, situada ya en el hemisferio sur y alineada en dirección NE-SW con Santo Tomé y Príncipe.

Desde una perspectiva biogeográfica ha despertado, sobre todo la isla, un gran interés, al estar situado en ella el pico Basilé (antiguamente Santa Isabel, y en inglés Clarence Peak), que alcanza los $3000 \mathrm{~m}$ y que dista unos pocos km del pico Camerún, de más de $4000 \mathrm{~m}$, situado en el continente africano, en Camerún, al NE de la isla. Bioko está formada por un estratovolcán dominante, que es el pico citado y una caldera en el S abierta hacia el litoral, aparato volcánico de más de $2000 \mathrm{~m}$ de altitud. La zonación de la vegetación ha sido

\begin{abstract}
Morales, R. 2011. Labiates (Lamiaceae) from Equatorial Guinea. Anales Jard. Bot. Madrid 68(2): 199-223 (in Spanish).

The identification of 223 collections of the Lamiaceae family, from Bioko island, Rio Muni (Equatorial Guinea mainland) and Annobon, corresponding to 14 genera and 28 species, is presented. A key of genera and, in each genus, a key of species are included. The basionym and type material, a brief description, the known chromosomic numbers, the distribution area and some known popular uses from each species, also included are photographs of sheets and distribution maps. Some biogeographical aspects about the generic and specific distribution in the studied area are discussed. Calaminta pseudosimensis (Brenan) R. Morales, comb. nov. is proposed.
\end{abstract}

Keywords: Lamiaceae, Equatorial Guinea, Bioko, Equatorial Guinea mainland, Annobon, chorology.

tratada extensamente en muy diferentes trabajos en distintas lenguas (español, alemán, inglés) desde antiguo.

Con motivo de diferentes intentos de la elaboración de una flora de dicho país, hasta la que en la actualidad está en curso, se han estudiado entre otras familias la de las labiadas. Dicha familia tiene poca trascendencia florística en las regiones tropicales, como se concluye después de realizar el presente trabajo.

En este se han seguido por lo general las directrices que se plasman en la actual Flora de Guinea, de la que ya han sido publicados 2 volúmenes de los 11 previstos: el I, que corresponde a los helechos, en 2008, y el $\mathrm{V}$, sobre las leguminosas, en 2010.

Respecto al criterio seguido en la delimitación de la familia Labiatae ha sido el anterior a la última revisión que se hizo por Harley \& al. (2004), dado que se distinguían bien las especies y géneros como pertenecientes a dicha familia, fundamentado en sus caracteres morfológicos, sin tener en cuenta los estudios de los últimos 20 años sobre filogenia, que han pretendido acla- 
rar la sistemática de la familia sin avances apreciables. Por lo tanto no se incluyen los géneros de Verbenaceae con inflorescencia cimosa, Clerodendrum, Premna y Vitex, recientemente transferidos a las Labiatae.

\section{Metodología}

Se han estudiado e identificado todas las labiadas colectadas en diversos territorios de Guinea Ecuatorial: isla de Bioko (antiguo Fernando Poo), Río Muni o región continental y la isla de Annobón. Se ha elaborado una clave de géneros. Los géneros y especies se disponen por orden alfabético. En los géneros que se componen de más de una especie en el territorio se incluye una clave de especies. De cada especie se cita el autor y basiónimo, indicación locotípica entrecomillada y material tipo si se conoce, lugar en donde se dispone de una descripción y de iconografía, incluyendo una fotografía de un pliego de la especie o una fotografía de la planta o de una lámina antigua en los casos en que no se dispone de iconografía. Después se incluye una pequeña descripción, número de cromosomas según datos de Morton (1962: 277-280), condiciones ecológicas e intervalo de altitud en el que se encuentra la especie, distribución en Guinea Ecuatorial, comentarios sobre su distribución general, y material que se conoce, en el que se reseñan todos los pliegos estudiados, los de herbario antiguos revisados y las citas bibliográficas. Para la indicación de los diferentes territorios se sigue el criterio de la Flora de Guinea Ecuatorial. La isla de Bioko se divide en Bioko Norte y Bioko Sur, y Río Muni, la región continental, en Litoral, Centro Sur, Kie Ntem y Wele Nzas. Se dispone de un mapa de distribución de cada especie, elaborado con coordenadas UTM en Bioko y geográficas en Río Muni. Se incluyen además datos sobre nombres vernáculos y usos de las diferentes especies. Al final se hace una discusión biogeográfica atendiendo a la composición florística a nivel genérico.

En la Tabla 1 se reseñan todas las especies presentes y los territorios en donde viven, indicando además si son alóctonas. En el apartado de consideraciones biogeográficas, en la Tabla 2 se citan todas las especies de labiadas que viven en los países vecinos Camerún, Gabón y Santo Tomé y Príncipe. Finalmente hay un Índice taxonómico.

\section{Catálogo}

Observaciones. Además de los 14 géneros que se consideran a continuación, Nosti (1955: 292-295) indica que Aeolanthus pubescens Benth. se encontraba en las fincas de braceros en Bioko y se consumía como verdura; que Mentha spicata L. (como M. sativa L.), la hierbabuena, se cultivaba en las fincas Sampaka, Po- tau y Domenech y en la Granja de Santa Isabel, y se usaba como condimento; que Tinnea barteri Gürke se cultivaba como ornamental en la Granja de Santa Isabel; y que Salvia coccinea Buchoz, salvia aromática oriunda de América, se conocía como ornamental de algunos pocos lugares.

Tabla 1. Especies estudiadas y su presencia en los distintos territorios estudiados. B, Bioko; A, Annobón; R, Río Muni; al., alóctona.

\begin{tabular}{|c|c|}
\hline Especie & Origen \\
\hline Achyrospermum oblongifolium & B \\
\hline Calamintha pseudosimensis & B \\
\hline Hoslundia opposita & $B, A, R$ \\
\hline Hyptis lanceolata & $B, R$ \\
\hline Hyptis suaveolens (al.) & $\mathrm{R}$ \\
\hline Isodon ramosissimus & B \\
\hline Leonotis nepetifolia (al.) & $B, A$ \\
\hline Leucas deflexa & B \\
\hline Leucas martinicensis (al.) & B \\
\hline Micromeria punctata & B \\
\hline Nepeta robusta & B \\
\hline Ocimum americanum (al.) & B \\
\hline Ocimum basilicum (al.) & $B, A$ \\
\hline Ocimum gratissimum (al.) & $B, A, R$ \\
\hline Platostoma africanum & $B, R$ \\
\hline Plectranthus assurgens & B \\
\hline Plectranthus cataractarum & B \\
\hline Plectranthus decurrens & $B, R$ \\
\hline Plectranthus epilithicus & $\mathrm{B}, \mathrm{R}$ \\
\hline Plectranthus glandulosus & B \\
\hline Plectranthus inselbergi & $\mathrm{R}$ \\
\hline Plectranthus monostachyus & $B, A, R$ \\
\hline Plectranthus occidentalis & $B, R$ \\
\hline Plectranthus punctatus & B \\
\hline Plectranthus rotundifolius (al.) & B \\
\hline Pycnostachys meyeri & B \\
\hline Stachys aculeolata & B \\
\hline Stachys pseudohumifusa & B \\
\hline
\end{tabular}




\section{CLAVE DE GÉNEROS}

1. Inflorescencia en espiga densa generalmente terminal .... 2

1. Inflorescencia en cima dicótoma con aspecto de panícula, axilar o terminal, en ejes simples o ramificados con verticilastros \pm aproximados, en glomérulos, o esféricas ........... 3

2. Inflorescencia sin dientes del cáliz espinosos sobresalientes 1. Achyrospermum

2. Inflorescencia con dientes del cáliz espinosos sobresalientes 13. Pycnostachys

3. Inflorescencia en cima dicótoma con aspecto de panícula, axilar o terminal

5. Isodon

3. Inflorescencia en ejes simples o ramificados con verticilastros \pm aproximados, en glomérulos, o esféricas

4. Inflorescencia en glomérulos densos sobre el par de brácteas foliáceas, como las hojas de cada nudo ........................ 5

4. Inflorescencia en ejes simples o ramificados con verticilastros, o globosa sin brácteas foliáceas ............................. 6

5. Cáliz de más de $13 \mathrm{~mm}$; corola sobresaliente, color naranja o rojiza ................................................... 6. Leonotis

5. Cáliz de menos de $11 \mathrm{~mm}$; corola blanquecina o crema......

7. Leucas

6. Inflorescencia esférica o cáliz con dientes dispuestos perpendiculares al tubo en la fructificación ............ 4. Hyptis

6. Inflorescencia en ejes simples o ramificados con verticilastros \pm densos; cáliz con dientes nunca perpendiculares al tubo

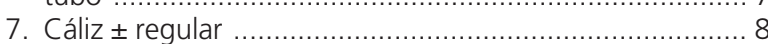

7. Cáliz zigomorfo ...................................................... 11

8. Planta trepadora; tallos con frecuencia de sección redondeada o hexagonal; cáliz que engorda en la fructificación a modo de fruto carnoso

3. Hoslundia

8. Planta no trepadora; tallos de sección cuadrangular; cáliz seco en la fructificación ... 9

9. Hojas de menos de $1 \mathrm{~cm}$, enteras; cáliz 2,5-4 mm

\section{Micromeria}

9. Hojas de más de 1,5 cm, dentadas; cáliz de más de $4 \mathrm{~mm}$.

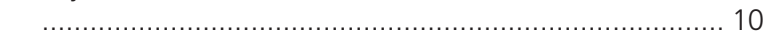

10. Planta leñosa, sobre todo abajo; tallos densamente pelosos; hojas subsésiles

9. Nepeta

10. Planta herbácea; tallos pelosos con acúleos; hojas con largo pecíolo

14. Stachys

11. Corola con tubo doblado hacia abajo y labio inferior aquillado

12. Plectranthus

11. Corola con tubo \pm derecho

12

12. Inflorescencia con brácteas como las hojas ... 2. Calamintha

12. Inflorescencia sin brácteas o con éstas muy pequeñas, muy diferentes de las hojas

13

13. Cáliz 4-6 mm en la fructificación, en general con labio superior orbicular, cóncavo

10. Ocimum

13. Cáliz de menos de $3 \mathrm{~mm}$, acampanado .. 11. Platostoma

\section{Achyrospermum Blume}

Género con unas 25 especies, que se extienden desde África tropical a través de las islas del Índico hasta la India, Nepal, S de China, Tailandia, Indonesia y Filipinas (Ryding in Harley \& al., 2004: 216).

1. A. oblongifolium Baker, Fl. Trop. Africa 5: 464 (1900)

Tipo: “Upper Guinea. Fernando Po, Barter, 1697!". Descripción: Baker, Fl. Trop. Africa 5: 464 (1900) Iconografía: Fig. 1.
Planta 0,2-0,8 m, herbácea, erguida, con tallos densamente pelosos. Hojas 10-17 × 3-6,5 cm, pecioladas, elípticas, levemente dentadas, pelosas solamente en los nervios. Inflorescencia 3,5-8 $\times 2 \mathrm{~cm}$, en espiga densa, cortamente pedunculada, generalmente terminal, con brácteas ovadas, ciliadas. Cáliz c. $10 \mathrm{~mm}$, ligeramente crateriforme, con 5 dientes \pm iguales, ciliados. Corola c. $7 \mathrm{~mm}$, delgada, color blanco. $2 n=28$.

Bosque denso y húmedo; 200-900 m. Bioko (Fig. 2). Según Morton (1963: 469), se encuentra también en Guinea, Sierra Leona, Liberia, Costa de Marfil, Ghana, Nigeria y Camerún; también en Santo Tomé y Cabinda; en MA hay un pliego del Congo. Exell (1973: 387) lo da para Santo Tomé.

\section{Material estudiado}

Bioko Norte: Malabo-Cupapa, km 22-23, márgenes del río Ejoa, 32NMK9005, bosque primario denso y húmedo, 15-X-1989, Carvalho 4138 (MA 514498). Herbácea de 60-80 cm. Flores blancas. Rara. Bioko Sur: Bokoko, häufig, X-1911, Mildbraed 6863 (Mildbraed 1922: 190). Musola, trocha, [32NMJ5780], 10-I-1947, Guinea 1150 (MA 514604). Las Costeras, [32NMJ6569], 28-I1947, Guinea 2103 (MA 254575). Belebú-Balachá, 32NMJ5375, 920 m, bosque denso, 28-II-1989, Fernández Casas 12143, R. Mo-

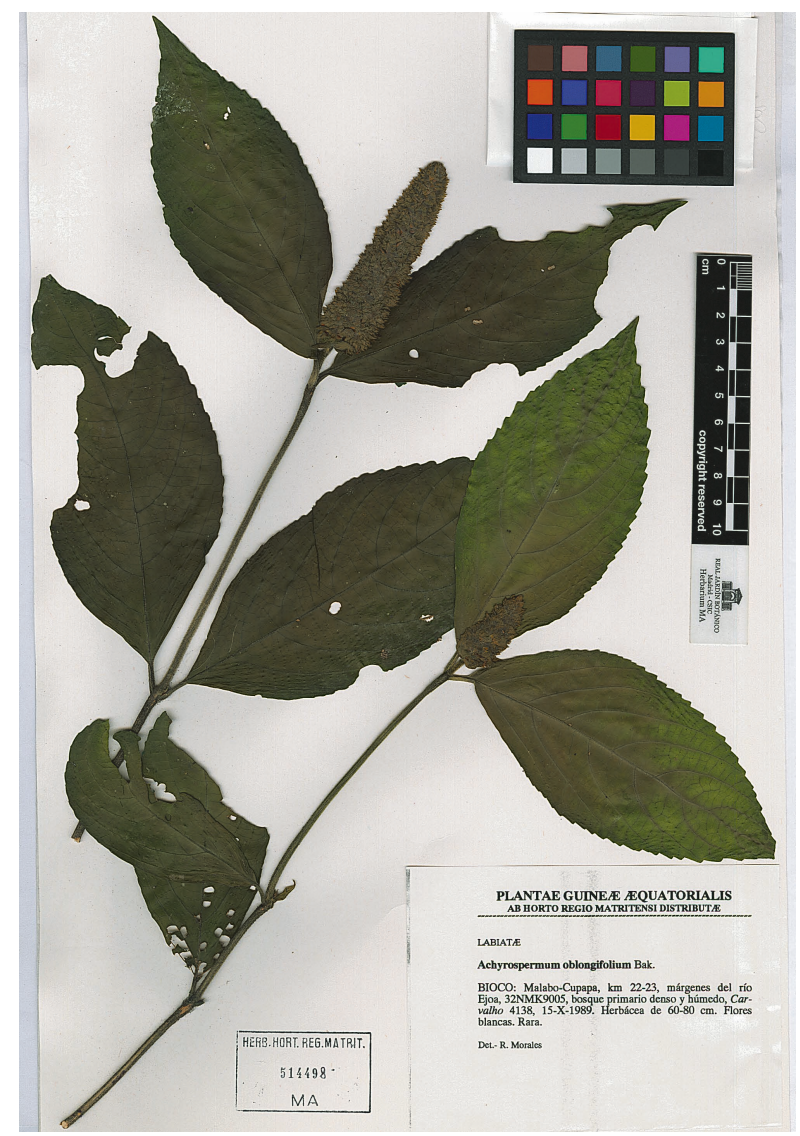

Fig. 1. Achyrospermum oblongifolium (MA 514498). 


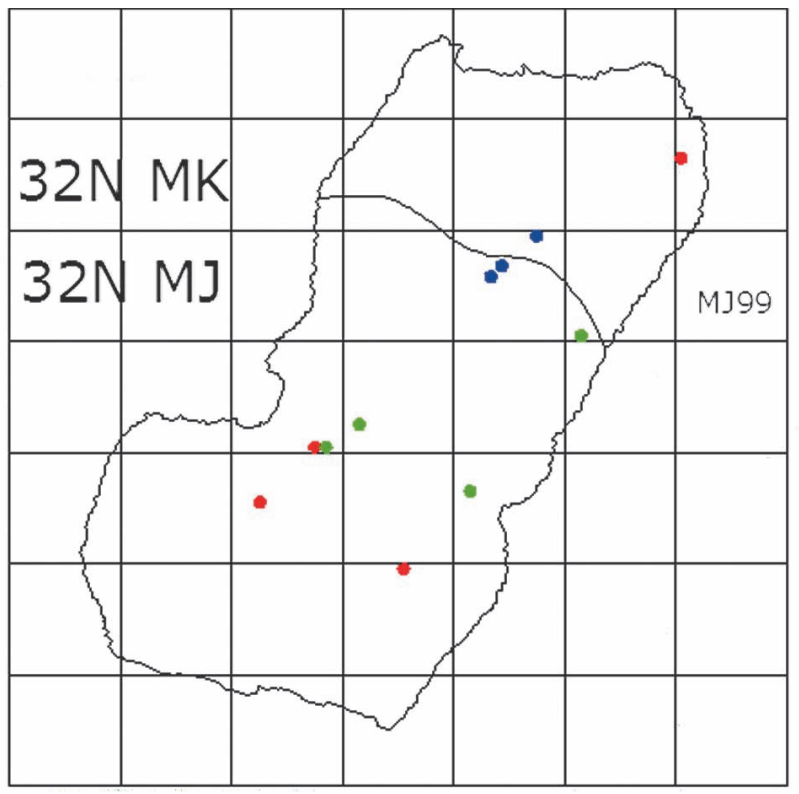

Fig. 2. Distribución en Bioko de Achyrospermum oblongifolium $(\bullet)$, Calamintha pseudosimensis (•) y Hoslundia opposita (•).

rales $\&$ al. (MA 533938). Flores blancas. Bioko: VI, XII-1858, Barter 1697 (Morton, 1963: 469, 25.3). Boughey 164 (Morton, 1963: $469,25.3)$.

\section{Calamintha Miller}

Consta de unas 20 especies, que viven en las regiones templadas y en las montañas tropicales de Eurasia, África y América.

1. C. pseudosimensis (Brenan) R. Morales, comb. nov.

Satureja pseudosimensis Brenan, Mem. New York Bot. Garden 9(1): 50 (1954)

Tipo: I.R. Dale 2157, K (holótipo).

Descripción: Seybold, Stuttgarter Beitr. Naturk., Ser. A, 421: 7 (1988).

Iconografía: Fig. 3.

Planta 0,3-0,6 m, postrada, ascendente, de aspecto herbáceo, que forma pequeñas colonias, con tallos pelosos. Hojas 0,6-1,6 × 0,4-1 cm, con pecíolos muy cortos, ovadas, crenadas, pelosas. Inflorescencia en verticilastros, con brácteas como las hojas. Cáliz 5-7 mm, zigomorfo, peloso; labio superior con 3 dientes triangulares e inferior con 2 largos, curvados hacia arriba, ciliados. Corola hasta de $10 \mathrm{~mm}$, color azul o púrpura. $2 n=22$.

Praderas con matorral, a veces en bosque primario o en márgenes de carretera; 2050-3000 m. Bioko, en la zona del pico Basilé (Fig. 2). Guinea (1949: 259) ya la cita para Bioko. Según Morton (1963: 467), se en- cuentra también en Camerún, Congo, Sudán, E de África y Nyasaland. Seybold (1988: 7) la considera como especie que vive en África tropical.

La separación de esta especie dentro de este género es justificada claramente por Morton (1962: 260), aunque luego él mismo la considere incluida dentro del género Satureja s.l. Se propone la anterior combinación, ya que el material tipo que se ajusta a la planta que vive en Bioko es Satureja pseudosimensis Brenan, y no Calamintha simensis Bentham $[=S$. simensis (Bentham) Briquet]. Esta última especie tiene las hojas pecioladas, menos pelosas, y cáliz más pequeño y apenas peloso.

\section{Material estudiado}

Bioko Norte: Carretera al pico Basilé, km 20, 32NMJ7799, 2050 m, bosque primario, 11-XI-1986, Carvalbo 2683 (MA 514507). Herbácea postrada. Flores azuladas. Bioko Sur: Grasflur des Gipfels, 16-XI-1911, Mildbraed 7172 (Mildbraed, 1922: 190). Pico Santa Isabel, 1-III-1947, Guinea 2662, 2674, 2695, 2820, $2860 b$ (MA 514648). Pico Basilé, 3007 m, 3-VI-1984, S. Castroviejo 9149 (MA 715604). Cumbre del pico Basilé, 32NMJ7396, 2950 m, pradera-matorral con brezos, 3-VII-1986, Fernández Casas 10172 E al. (MA 533941), $30 \mathrm{~cm}$. Flores azules. Carretera al pico Basilé,

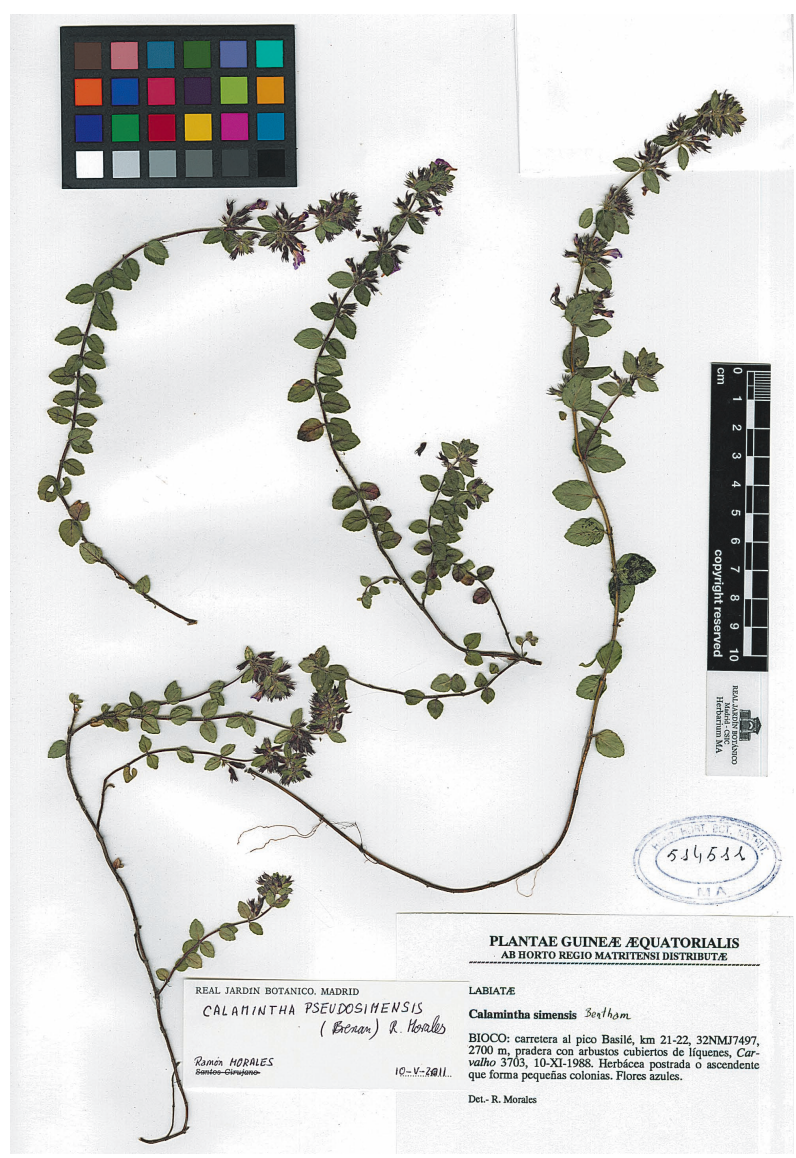

Fig. 3. Calamintha pseudosimensis (MA 514511). 
km 21-22,32NMJ7497, $2700 \mathrm{~m}$, pradera con arbustos cubiertos de líquenes, 10-XI-1988, Carvalbo 3703 (MA 514511). Herbácea postrada o ascendente que forma pequeñas colonias. Flores azules. Cumbre del pico Basilé, 32NMJ7396, 3000 m, bordes de carretera, 5-II-1989, Fernández Casas 11181, R. Morales E al. (MA 514617). Carretera al pico Basilé, km 21, 32NMJ7497, 2600 m, márgenes de la pista, 5-II-1989, Fernández Casas 11218, R. Morales E al. (MA 514622). Flores de color azul. Clarence Peak, $8500 \mathrm{ft}$ [2590 m], XII-1860, Mann 617. Herbaceous plant $60 \mathrm{~cm}$ high, calyx green, corolla purple (Brenan, 1. c.; Morton, 1963: 467, 22.2); como Satureja pseudosimensis Brenan. Cumbre del pico Santa Isabel, 1-III1947, Guinea 2821 (Brenan, 1. c.; Morton, 1963: 467, 22.2); como Satureja pseudosimensis Brenan. Lope del Val (Guinea 630) (MA 714071). Pico Jenaro, 9-I-1947, Guinea 2822 (MA 185650) [por el número se trata del pico Santa Isabel; fecha errónea].

\section{Hoslundia Vahl}

Género monoespecífico y exclusivamente africano (Paton in Harley \& al., 2004: 261).

\section{H. opposita Vahl, Enum. Pl. 1: 212 (1804)}

Tipo: "Habitat in dumetis Aquapim Guineae Thoning".

Descripción e iconografía: J. Berhaut (1975). Fl. ill. Sénégal 4: 174-175.

Bejuco sarmentoso, 1,3-4 m, denso, enmarañado, con tallos con pelos muy pequeños en los cantos. Hojas 7-12 $\times 2,5-5 \mathrm{~cm}$, opuestas o en verticilos de 3 , pecioladas, atenuadas en la base, elípticas, acuminadas, con pelos muy pequeños en los nervios. Inflorescencia en panícula en general terminal. Cáliz 1,5-4,5 mm, acrescente, regular, con 5 pequeños dientes, cuando maduro engordado, c. 4,5 mm de diámetro, globoso, color amarillo o anaranjado, con pelos glandulares. Corola c. $4 \mathrm{~mm}$, color blanco o crema. $2 n=24$.

Bosques primario o secundario, o en lindes; 250540 m. Bioko, Annobón y Río Muni (Figs. 2, 4). Según Morton (1963: 456) vive en toda África tropical, Sudáfrica y Madagascar.

Esta planta es diseminada al parecer por aves que comen su frutillo.

\section{Material estudiado}

Bioko Norte: Malabo-Riaba, barrancos junto al puente sobre el río Cope, 32NMJ8190, 250 m, bosque primario, 14-IV-1990, Carvalho 4322 (MA 514525). Herbácea de 1,3 m. Flores blancas. Frutos globosos, amarillos. Bioko Sur: Musola, cerca de Bombe, a 5 $\mathrm{km}$ del cruce, 32NMJ6182, $540 \mathrm{~m}$, bosque secundario, 15-VIII1986, Carvalho 2327 (MA 533931). Bejuco, 2-3 m. Flores blancas o cremas. Forma pequeñas marañas. Entre Malabo y Riaba, km 60, 32NMJ7176, bosque primario denso, 23-V-1987, Carvalho 2924. (MA 514506). Herbácea, 2-3 m. Flores blancas. Frutos amarillos hinchados. Entre el cruce de Moca y Riaba, km 7,5, 32NMJ5880, $400 \mathrm{~m}$, lindes de bosque, 13-II-1989, Fernández Casas 11602, R. Morales E al. (MA 514643). Bejuco sarmentoso de $4 \mathrm{~m}$. Flores blancas, frutos anaranjados. Bioko: Mann 264 (Morton, 1963: 456, 10). Annobón: Fields in the $N$ of the island, [1 $\left.{ }^{\circ} 26^{\prime} \mathrm{S} 5^{\circ} 38^{\prime} \mathrm{E}\right]$, Newton (LISU). Small shrub; whitish flowers, not scented. (Exell,
1956:39). Centro Sur: Bata-Niefang-Monte Alén, carretera km 9091, próximo al límite de Niefang-Evinayong, [141'N 10²18'E], bosque primario, 16-VI-1995, Carvalho 5912 (MA 609866). Herbácea de aspecto trepador, densa y enmarañada. Flores blancas y frutillos hinchados. Rara no local.

\section{Hyptis Jacquin}

Género con unas 280 especies, todas americanas excepto algunas que viven en los trópicos del viejo mundo, algunas de ellas introducidas (Harley in Harley \& al., 2004: 259).

1. Hojas con pecíolo corto, atenuadas en la base; inflorescencia pedunculada, esférica; cáliz maduro hasta de $5 \mathrm{~mm}$.....

1. H. lanceolata

1. Hojas con pecíolo largo, cordadas en la base; inflorescencia pedunculada en verticilos con pocas flores; cáliz hasta de $10 \mathrm{~mm}$

2. H. suaveolens

1. H. lanceolata Poiret in Lam., Encycl., Suppl. 3: 114 (1813)

H. brevipes sensu Fl. Trop. Africa 5: 447 (1900)

Tipo: "Je soupçonne cette plante originaire de l'Amérique ? (V. s. in herb. Desf.)".

Descripción e iconografía: J. Berhaut (1975). Fl. ill. Sénégal 4: 178-179.

Planta hasta de $1,5 \mathrm{~m}$, herbácea, con tallos con algunos pelos en los cantos. Hojas $5-13 \times 2-3,5 \mathrm{~cm}$, cortamente pecioladas, atenuadas en la base, elípticas, \pm dentadas, con algunos pelos en los nervios. Inflorescencia 1,3-1,7 cm de diámetro, esférica, 2 por nudo, pedunculada, con brácteas lanceoladas que apenas sobresalen. Cáliz hasta de $5 \mathrm{~mm}$, con 5 dientes rectos. Corola color blanco. $2 n=32$.

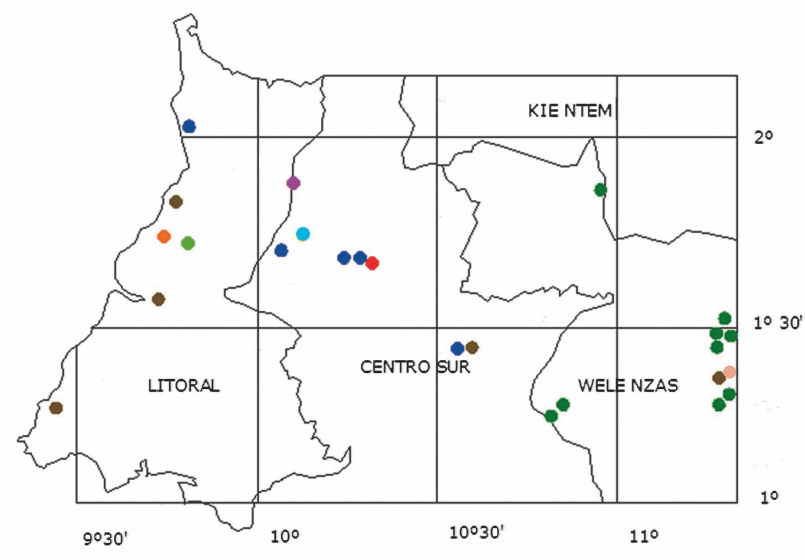

Fig. 4. Distribución en Río Muni de Hoslundia opposita (•), Hyptis lanceolata $(\bullet), H$. suaveolens $(\bullet)$, Platostoma africanum $(\bullet)$, Plectranthus decurrens $(\bullet), P$. epilithicus $(\bullet), P$. inselbergi $(\bullet), P$. monostachyus $(\bullet)$ y $P$. occidentalis $(\bullet)$. 
Lindes de bosque y praderas, junto a sendas; 2001720 m. Bioko y Río Muni (Figs. 4, 5). Según Morton (1963: 467), es nativa en gran parte de África occidental, área en donde vive, y se extiende a toda África tropical. También vive en América.

\section{Material estudiado}

Bioko Norte: 600-800 m, VIII-1911, Mildbraed 6264 (Mildbraed, 1922: 191). Bioko Sur: Grasland Moka, X-XI-1911, Mildbraed 7079 (Mildbraed, 1922: 191). Cercano y al S de Moca, camino de las cascadas de Iladyi, 32NMJ6368, $1250 \mathrm{~m}$, praderas, 16-VII1986, Fernández Casas 10431 E al. (MA 514528). Herbácea. Moca, 32NMJ6369, 1270 m, lindes de bosque, 18-II-1989, Fernández Casas 11712, R. Morales E al. (MA 514629). Flores blancas. Entre el borde de la caldera del lago Biaó y Moca, 32NMJ5970, 1720 m, linde de bosque, 22-II-1989, Fernández Casas 11981, R. Morales E al. (MA 514637). Musola, Servicio Agronómico, [32NMJ5780], 9-I1947, Guinea 987 (MA 255011), Guinea 1062, 1065 (MA 537710). Bioko: Tofre [Toho?] 11-II-1939, Lope del Val 70 (MA 713777). Lope del Val (Guinea 498) (MA 713779). VI-1858, Barter s.n. (Morton, 1963: 467, 21.5). XII, Monod 10489 (Morton, 1963: 467, 21.5). Tessmann 2820, 2854 (Mildbraed 1922: 191). 1841, Vogel 22 (Mildbraed 1922: 191). Litoral: Entre Utonde y Punta Mbonda y Mepemba, [2²'N 948'E] (Guinea, 1946: 159). Centro Sur: Evinayong, [1 $\left.{ }^{\circ} 27^{\prime} \mathrm{N} 10^{\circ} 34^{\prime} \mathrm{E}\right]$, 20-VI-1945, Guinea 311 (MA 514646). Monte Alén, praderas pasado el mirador, $1^{\circ} 39^{\prime} \mathrm{N} 10^{\circ} 17^{\prime} \mathrm{E}, 8-\mathrm{VIII}-$ 2001, F. Cabezas 133 (MA 695702). “onkomiken”. Monte Alén, subida al mirador, senda en el bosque, $1^{\circ} 39^{\prime} \mathrm{N} 10^{\circ} 18^{\prime} \mathrm{E}$, 8-VIII2001, F. Cabezas 131b (MA 698134). "esibokon". Mosumo, camino de las cataratas, $1^{\circ} 43^{\prime} 37^{\prime} \mathrm{N} 10^{\circ} 4^{\prime} 39^{\prime}$ "E, $200 \mathrm{~m}$, borde de camino, 8-VII-1999, Aedo 5102 E al. (MA 713766). Herbácea, 1,5 m.

Nombres vulgares: Onkomiken, esibokon (Río Muni).

2. H. suaveolens (L.) Poit., Ann. Mus. Paris 7: 472 t. 29 fig. 2 (1806)

Ballota suaveolens L., Syst. Nat., ed. 10, 2: 1100 (1759)

Tipo: "Habitat in America meridionali" [Sp. Pl. ed. 2 2: 815 (1763)]. Lectótipo: LINN 737.6 (Browne).

Descripción e iconografía: J. Berhaut (1975). Fl. ill. Sénégal 4: 186-187.

Planta de unos $0,8 \mathrm{~m}$, herbácea, con tallos con pelos dispersos. Hojas 4,5-7,5 × 2-3,5 cm, con pecíolos largos, cordadas en la base, ovadas, irregularmente aserradas, con envés blanquecino debido a la pilosidad. Inflorescencia en verticilastros pedunculados con pocas flores. Cáliz hasta de $10 \mathrm{~mm}$; tubo con nervios bien marcados, peloso, con 5 dientes de c. $2 \mathrm{~mm}$, en disposición perpendicular al tubo después de la antesis. Corola c. $6 \mathrm{~mm}$, color azulado. $2 n=32$.

Bosque secundario. Río Muni (Fig. 4). Según Morton (1963: 466) es oriunda de América e introducida en África occidental. Se extiende por África tropical.

\section{Material estudiado}

Litoral: Bata-Bi[Ma]como, estrada km 5-6, bosque secundario

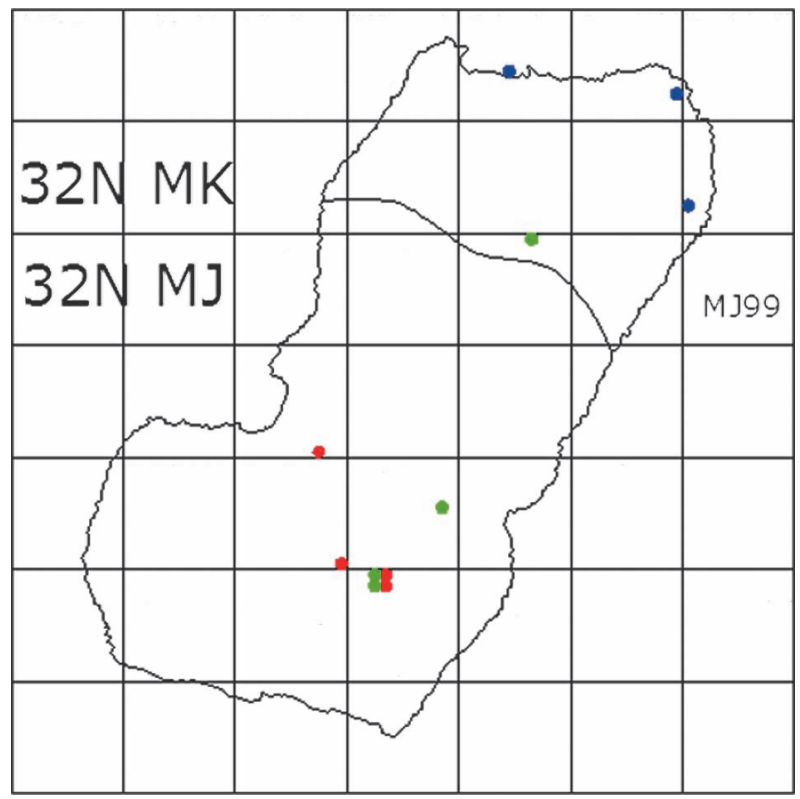

Fig. 5. Distribución en Bioko de Hyptis lanceolata (•), Leonotis

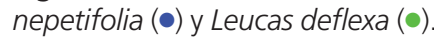

con algunos árboles de bosque primario, 15-VIII-1991, Carvalho 4780 (MA 597582). 80 cm. Herbácea. Flores color lila. Abundante.

Nombre vulgar: Ocim (fang, en Carvalho 4780).

Usos: Planta muy aromática, parecida a la albahaca (Ocimum basilicum). Las hojas se utilizan como condimento.

\section{Isodon (Bentham) Schrader ex Spach incl. Homalocheilos}

Género con unas 100 especies (Paton in Harley \& al., 2004: 256), aunque la monografía de Li (1988) considera 96 especies. Casi todas ellas viven en el S y C de China e India y llegan hasta Japón y Corea como límite de área por el $\mathrm{E}$ y al continente africano como límite de área por el W. De África se conocen dos especies. Pertenece este género a la tribu Ocimeae subtribu Hanceolinae. Morton describió el nuevo género Homalocheilos para las dos especies africanas. Desde el punto de vista morfológico dicho género parece insostenible.

1. I. ramosissimus (Hooker fil.) Codd, Taxon 17(2): 239 (1968)

Plectranthus ramosissimus Hooker fil., J. Proc. Linn. Soc., Bot. 6: 17 (1862)

Homalocheilos ramosissimus (Hooker fil.) J.K. Morton, J. Linn. Soc., Bot. 58: 268 (1962)

Tipo: "Hab. In Fernando Po, alt. 5000 ped. (fl. Dec.)". Lectótipo: Fernando Poo, Clarence Peak, 5000 ft., 1860, Mann 624 (K); isótipo: en A. 
Descripción e iconografía: J.K. Morton (1962). J. Linn. Soc., Bot. 58: 268.

Planta 1-3 m, herbácea, postrada o ascendente, con tallos pelosos en los cantos. Hojas 3,5-7 × 1,2-2,5 cm, pecioladas, \pm truncadas en la base, ovadas, agudas, aserradas, en general con pelos dispersos, densamente pelosas en los pecíolos y nervios, con envés blanquecino. Inflorescencia en panícula de cimas dicótomas, con muchas flores. Cáliz 2,5-4 mm, acrescente, curvado, con 5 dientes triangulares. Corola c. $6 \mathrm{~mm}$, con 4 lóbulos superiores iguales y uno inferior triangular, color blanco con manchas negras. $2 n=42$.

Bosques, lindes, taludes de carretera, bordes de prados, en arbustos o helechales; 400-1880 m. Bioko (Fig. 6). Según Morton (1963: 461) vive también en Sudán, Camerún, Uganda y Rodesia.

La densidad de la pilosidad en esta especie es muy variable.

\section{Material estudiado}

Bioko Norte: Clarence Peak, 5000 ft [1500 m], 1860, Mann 624 (K). Carretera del pico Basilé, junto al observatorio, 32NMK7700, 1880 m, 5-II-1989, Fernández Casas 11172, R. Morales E al. (MA 539547, MA 544414). Escandente, 2 m. Bioko Sur: Musola, häufig, XI-1911, Mildbraed 7002 (Mildbraed, 1922: 191). Grasland Moka, sehr häufig, blüht X-XI, XI-1911, Mildbraed 7070 (Mildbraed, 1922: 191). Carretera de Musola, [32NMJ5582], 11-I-1947, Guinea 1233 (MA 255502), 1241 (MA 514650), 1266. Moca, km 70, patio Mioco, 32NMJ6272, $1500 \mathrm{~m}$, bosque secundario, 21-IX1986, Carvalho 2488 (MA 514502). Herbácea de 2 m. Flores blancas. Malabo-Moca, km 68, 32NMJ6275, 1150 m, taludes de carretera, 24-X-1986, Carvalho 2611 (MA 514508). Herbácea postrada o ascendente. Flores blancas. Entre el cruce y Moca, 32NMJ6271, 1580 m, lindes de prados, 10-II-1989, Fernández Casas 11476, R. Morales \& al. (MA 533940). Herbácea, $1 \mathrm{~m}$. Flores blancas. Entre el cruce de Moca y Riaba, km 7,5, 32NMJ5880, 400 m, margen de la carretera, 13-II-1989, Fernández Casas 11600, R. Morales E al. (MA 514641). 1 m. Flores blancas con puntos negros. Moca, 32NMJ6369, 1270 m, pradera, 18-II-1989, Fernández Casas 11704, R. Morales E al. (MA 533939). 2 m. Entre Moca y Riaba por el camino viejo, 32NMJ6369, $1320 \mathrm{~m}$, lindes de bosque, 20-II-1989, Fernández Casas 11807, R. Morales E al. (MA 514630). Herbácea, $3 \mathrm{~m}$. Entre Moca y el lago Biaó, 32NMJ6170, $1440 \mathrm{~m}$, linde de bosque, 22-II-1989, Fernández Casas 11920, R. Morales E al. (MA 514632). 1,2 m. Flores blancas. Malabo-Moca, km 65-66 de Malabo y a 11-12 kms del cruce a Riaba, [32NMJ6073], arbustos con Pteridium aquilinum, 6-XI-1990, Carvalho 4536 (MA 514496). Herbácea postrado-ascendente de cerca de $2 \mathrm{~m}$. Flores blancas. [Pico San Joaquín, (32NMJ6071), 25-I-1947], Guinea 1979 (Morton, 1963: 461, 15). Bioko: III, XII, Monod 10430 (Morton, 1963: 461, 15). 1500 m, Tessmann 2848 (Mildbraed, 1922: 191). Mann 624 (Mildbraed, 1922: 191).

\section{Leonotis (Pers.) R. Br.}

Género africano con 10 especies (Ryding in Harley \& al., 2004: 228); L. nepetifolia vive en todas las regiones tropicales del mundo. Por ello no se sabe si es planta alóctona en la región estudiada.
1. L. nepetifolia (L.) R. Br. in W.T. Aiton, Hort. Kew. ed. 2, 3: 409 (1811)

Pblomis nepetifolia L., Sp. Pl. 2: 586 (1753)

Tipo: "Habitat Surinami? Iconotipo Cardiaca Americana annua Nepetae folio, floribus brevibus phoeniceis villosis" in Hermann, Hort. Lugd.-Bat. Cat.: 115, 117 (1687).

Descripción e iconografía: J. Berhaut (1975). Fl. ill. Sénégal 4: 192-193.

Planta 1-1,5 m, herbácea arbustiva, con tallos afelpados muy pelosos, inapreciable a simple vista. Hojas 5-7 $\times 2-4 \mathrm{~cm}$, largamente pecioladas, de cordadas a atenuadas en la base, ovadas, agudas, dentadas, a veces con dientes redondeados, afelpadas. Inflorescencia 3-5 cm de diámetro, en glomérulos densos, con bractéolas lanceoladas espinosas. Cáliz 13-20 mm, doblemente curvado, con diente superior mucho más largo que los otros 4, agudos. Corola c. $17 \mathrm{~mm}$, con largo tubo, afelpada, color naranja. $2 n=28$.

Bordes de carretera, junto a poblados; 0-50 m. Bioko Norte y Annobón (Fig. 5). Según Morton (1963: 470), que no la cita para Bioko, se extiende por toda África occidental y África tropical. Exell (1973:387, fam. 128) la cita para Bioko, Annobón, Santo Tomé y Príncipe.

Es planta cultivada.

\section{Material estudiado}

Bioko Norte: Proximidades obras públicas, alrededores de Santa Isabel, [32NMK7414], 23-IX-1942 [Guinea 1159] (MA

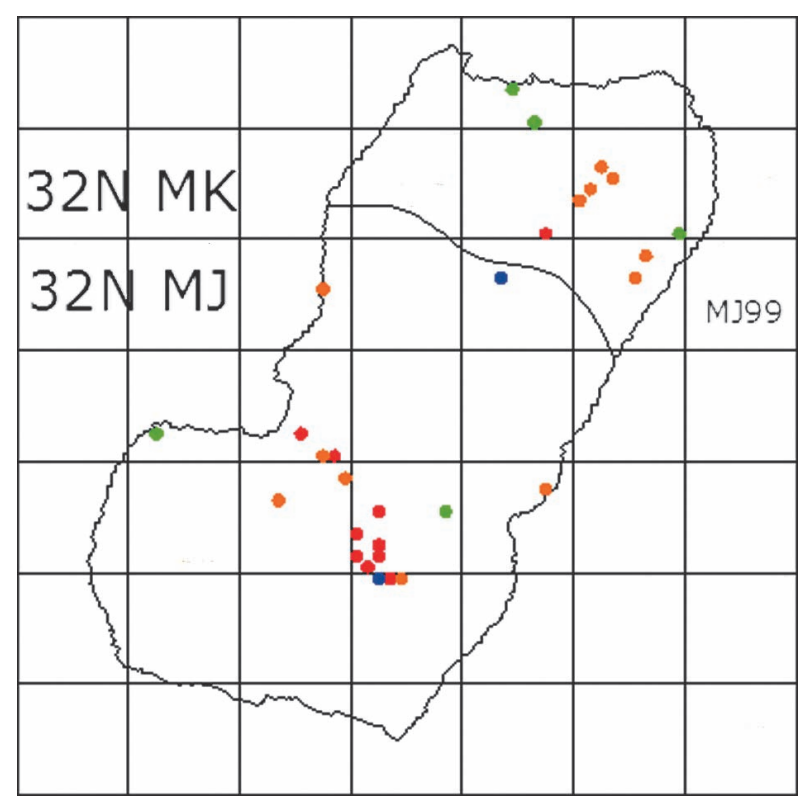

Fig. 6. Distribución en Bioko de Isodon ramosissimus (•), Leucas martinicensis $(\bullet)$, Ocimum gratissimum $(\bullet)$, Platostoma africanum (•). 
514608). Flores anaranjadas. Malabo-Riaba, cerca de Baó Basuala, $\mathrm{km}$ 26,5, 32NMK8902, $0 \mathrm{~m}$, lugares ruderalizados, 12-II-1989, Fernández Casas 11507, R. Morales E al. (MA 514625). 1,5 m. Cerca de Misión Basuala, km 26, 32NMK9002, terrenos incultos, 6IV-1990, Carvalho 4315 (MA 514523). Herbácea de 1,2 m. Flores rojas. Forma colonias reducidas. Annobón: Ambo, by our houses, [1 $\left.1^{\circ} 24^{\prime} \mathrm{S} 5^{\circ} 37^{\prime} \mathrm{E}\right], 50 \mathrm{ft}[15 \mathrm{~m}$ ], waste ground and common there, 13-VII-1959, Wrigley \& Melville 141 (MA 255187). Orange corolla (bright orange hairs). Natives dry and hang up to keep off mosquitoes. Palé, alrededores del campo de futbol, terrenos incultos, [1²4'S 5³8'E], 16-IX-1987, Carvalho 3107 (MA 514501). Herbácea de $1 \mathrm{~m}$. Flores rojas. Hojas bastante aromáticas. Anganchi, 1²6’3"S 5³9'5"E, 50 m, ruderal, 27-XI-2010, Aedo 18057 \& al. (MA 831274). Herbácea 1,7 m. Flor naranja.

Usos: Se seca la planta y se cuelga para que actúe como repelente de mosquitos (MA 255187).

\section{Leucas Burm. ex R. Br.}

Género con unas 100 especies que se extienden desde África tropical y del sur hasta el SE de Asia y Japón (Ryding in Harley \& al., 2004: 227). L. martinicensis es mala hierba cosmopolita en toda la región tropical.

1. Hojas lanceoladas; cáliz con dientes más cortos que el tubo, triangulares

1. L. deflexa
1. Hojas ovado-elípticas; cáliz con dientes tan largos como el tubo, largamente agudos

2. L. martinicensis

1. L. deflexa Hooker fil., J. Proc. Linn. Soc., Bot. 7: 213 (1864)

Tipo: "Hab. Cameroons Mountains, alt. 7000 feet. (Fl. Nov.-Feb)".

Iconografía: Figs. 7, 8.

Planta 0,8-1,5 m, erguida, con tallos afelpados. Hojas 4-7,5 $\times 1-2 \mathrm{~cm}$, pecioladas, atenuadas en la base, elípticas, agudas, dentadas con dientes hacia arriba, con pelos dispersos, densamente pelosa en los nervios. Inflorescencia 1,5-2,5 cm de diámetro, en glomérulos, con bractéolas lineares. Cáliz 5-10 mm, por arriba curvado hacia abajo, con 5 dientes espinosos, los 3 del labio inferior más largos, y algunas pequeñas espinas más, pelosos arriba. Corola c. $5 \mathrm{~mm}$, con labio superior redondeado y densamente ciliado, color blanco. $2 n=28$.

Borde de carretera, en bosquetes; $1250-2120 \mathrm{~m}$. Bioko (Fig. 5). Según Morton (1963: 470) se extiende por toda África occidental, en Ghana y Camerún, y también en Angola.

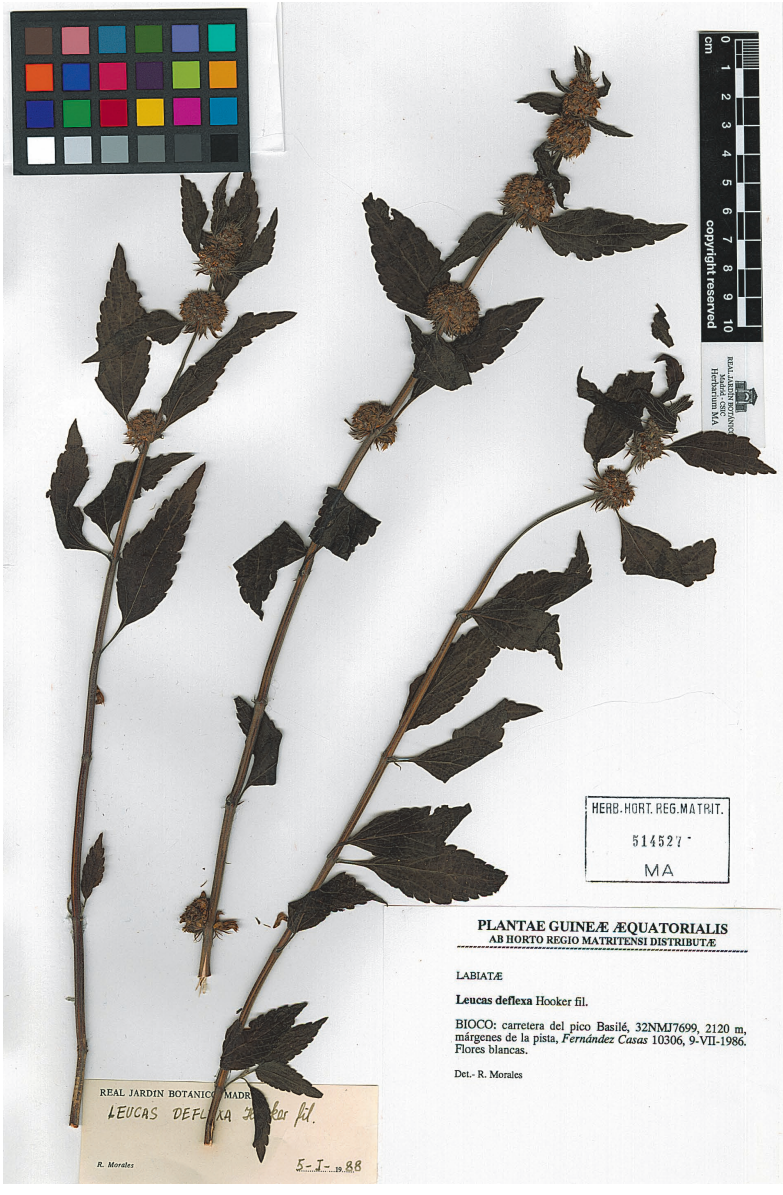

Fig. 7. Leucas deflexa (MA 514527).

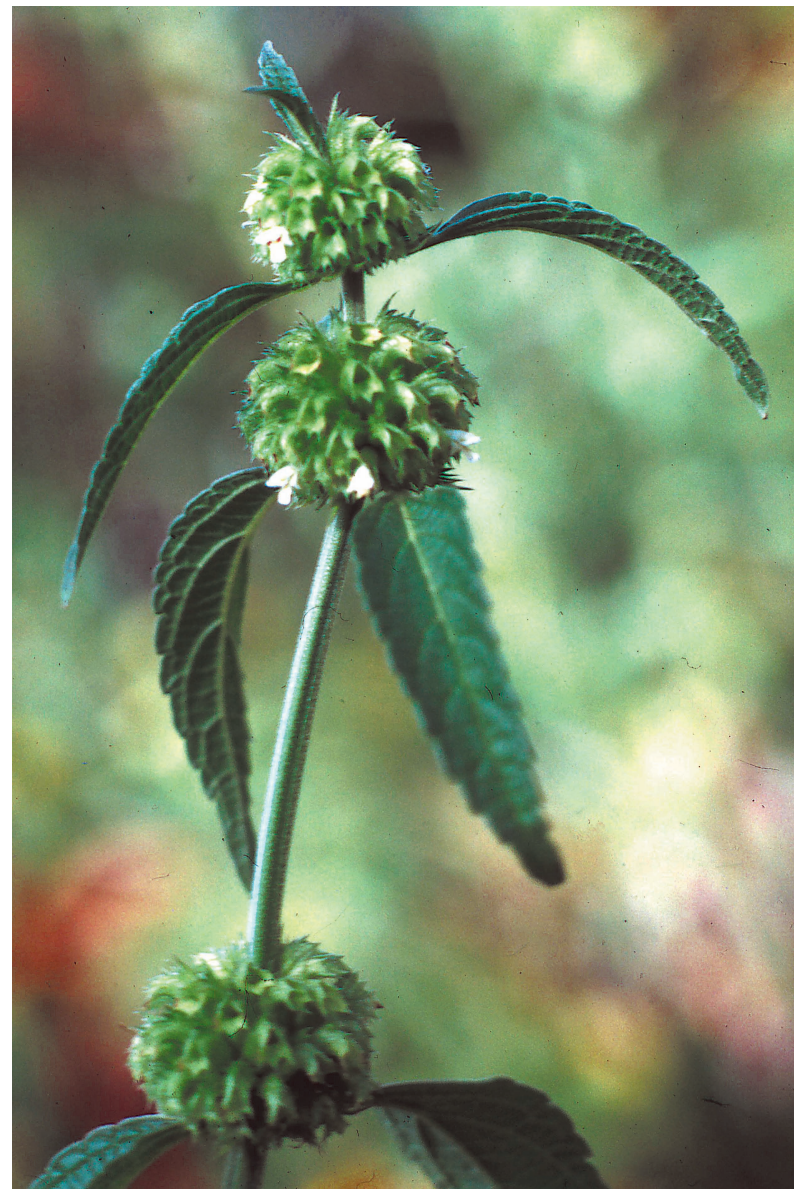

Fig. 8. Leucas deflexa, subida al pico Basilé, 5-II-1989, R. Morales. 


\section{Material estudiado}

Bioko Norte: Carretera del pico Basilé, 32NMJ7699, 2120 m, márgenes de la pista, 9-VII-1986, Fernández Casas 10306 E al. (MA 514527). Flores blancas. 4000-5000 ft [1200-1500 m], II, Exell 857 (Morton, 1963: 470, 27.2). Bioko Sur: Moka, [32NMJ6269], 1939, Lope del Val (MA 500436). Balachá, [32NMJ6875], 15-I-1947, Guinea 1500 (MA 255189), 1503. Moka, camino de Ureca, 32NMJ6268, $1250 \mathrm{~m}$, bosquetes, 18II-1989, Fernández Casas 11716, R. Morales E al. (MA 533936). 1,5 m. Flores blancas. Bioko: Boughey GC-10803 (Morton, 1963: $470,27.2)$.

2. L. martinicensis (Jacq.) R. Br. in W. T. Aiton, Hort. Kew. ed. 2, 3: 409 (1811)

Clinopodium martinicense Jacq., Enum. Syst. Plant.: $25(1760)$

Tipo: "In Insulis Caribaeis vicinaque Americes continente detexit novas".

Descripción e iconografía: J. Berhaut (1975). Fl. ill. Sénégal 4: 196-197.

Planta $25-60 \mathrm{~cm}$, herbácea, postrada, que forma pequeñas colonias, con tallos densamente pelosos. Hojas 1,6-3 $\times$ 0,5-1 cm, sentadas, elípticas, con hasta 3 pares de dientes poco marcados, muy pelosas. Inflorescencia 14-18 mm de anchura, en glomérulos densos, muy pelosos, con pelos blancos, con bractéolas estrechamente lanceoladas. Cáliz c. $6 \mathrm{~mm}$; dientes con largos pelos blancos. Corola c. $8 \mathrm{~mm}$, con labio superior densamente ciliado, color blanco. $2 n=28$.

Bioko Sur (Fig. 6). Según Morton (1963: 470) es una mala hierba del trópico. Al parecer es de origen americano.

\section{Material estudiado}

Bioko Sur: Cumbre del pico Basilé, 32NMJ7396, 2950 m, pradera-matorral con brezos, 3-VII-1986, Fernández Casas 10150 E al. (MA 514614). Flores blancas. Cumbre del pico Basilé, 32NMJ7396, 2870 m, prados cacuminales, 5-II-1989, Fernández Casas 11200, R. Morales \& al. (MA 514619). Flores blancas. Malabo-pico Basilé, carretera al pico, km 28-29, pradera con Hypericum revolutum, Lobelia columnaris, Clematis altissima y Adenocarpus mannii, 25-X-1990, Carvalho 4520 (MA 514497). Planta herbácea postrada, formando pequeñas colonias. Inflorescencia con flores blancas. Moka, [32NMJ6269], XII, Boughey 10 (Morton, 1963: $470,27.1)$.

\section{Micromeria Bentham}

Género con unas 70 especies que se distribuyen por Eurasia y África (Morales in Harley \& al., 2004: 240).

1. M. punctata Bentham, Labiat. Gen. Spec.: 378 (1834)

Satureja punctata (Bentham) Briquet in Engler \& Prantl, Nat. Pflanzenfam. IV 3A: 299 (1896)
Micromeria biflora var. punctata (Bentham) Fiori, Nouvo Giorn. Bot. Ital. 20: 371 (1913)

Tipo: "Habitat in Abyssinia Salt! (v. s. sp. in herb. Mus. Brit.)”. Lectótipo: Salt, Abessinien (BM).

Descripción: Seybold, Stuttgarter Beitr. Naturk., Ser. A, 421: 24 (1988).

Iconografía: Fig. 9.

Planta $15-35 \mathrm{~cm}$, leñosa, con tallos cortamente pelosos. Hojas 3-6 × 1,5-5 mm, con pecíolo corto, ovadas o elípticas, agudas, enteras, con nervio central y marginal marcados por el envés a lo largo de todo el contorno, pelosas en los nervios, punteadas con glándulas esferoidales. Inflorescencia hasta de $10 \mathrm{~cm}$, en verticilastros axilares densos, con brácteas como las hojas y bractéolas lineares de c. $1 \mathrm{~mm}$. Cáliz 2,5-4 mm, pedicelado, peloso, con 5 dientes hasta de $1 \mathrm{~mm}$, ciliados. Corola 6-8 mm, color púrpura claro. $2 n=30$.

Bordes de carretera o entre el matorral, $3000 \mathrm{~m}$. Bioko Sur en el pico Basilé (Fig. 10). Guinea (1949: 258) la cita para Bioko como Micromeria biflora Bentham. Morales (1990: 90) da como nueva esta planta para la isla, pasando por alto la cita de E. Guinea.

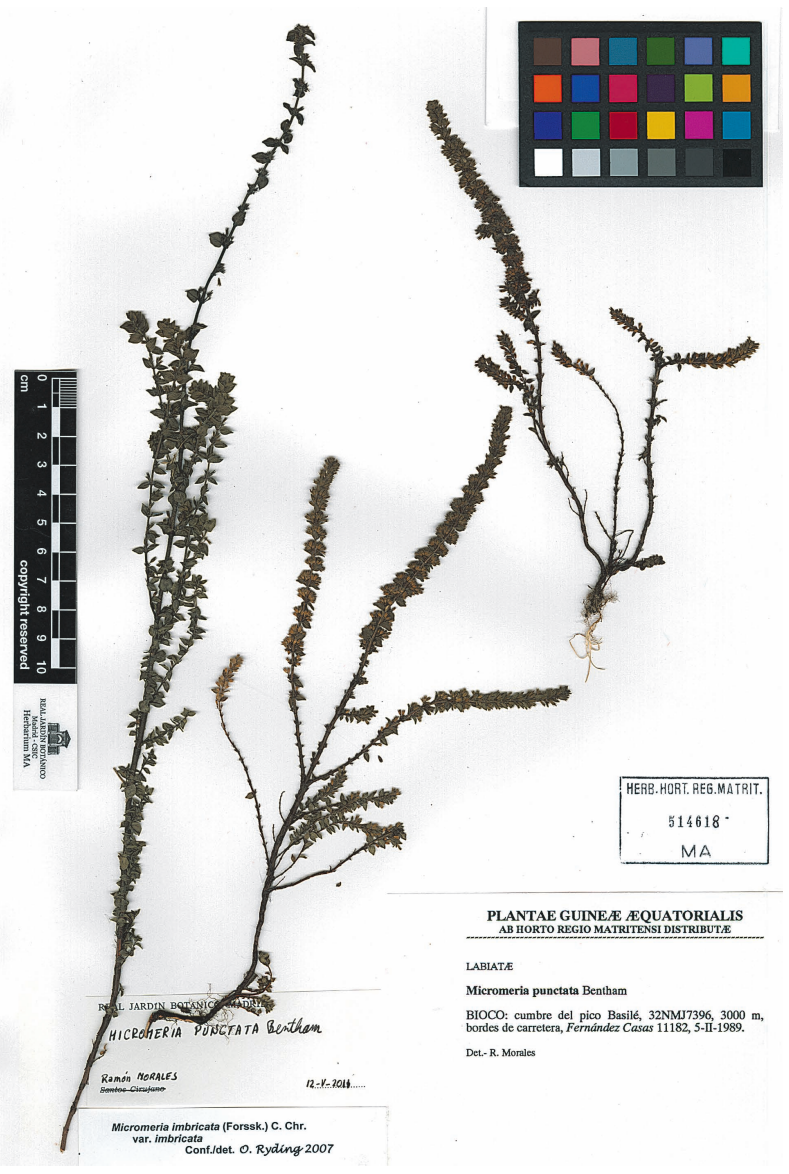

Fig. 9. Micromeria punctata (MA 514618). 
Exell (1973: 387, fam. 128) no la cita para Bioko. Se trata de una planta que vive en las montañas africanas desde el pico Camerún hasta Etiopía y el E y S de África (Morton, 1963: 467).

La pertenencia de esta especie a Micromeria es justificada claramente por Morton (1962: 260), aunque la considere incluida dentro de Satureja s.l. De acuerdo con Seybold (1988: 24) dicha especie no se sinonimiza a M. imbricata (Forsskal) Christensen, Dansk Bot. Arkiv 4(3): 21 (1922) var. imbricata, según propone Ryding (2007: 434).

\section{Material estudiado}

Bioko Sur: Pico Santa Isabel, \pm 3000 m, 1-III-1947, Guinea 2823b (MA 514613). Cumbre del pico Basilé, 32NMJ7396, 3000 m, bordes de carretera, 5-II-1989, Fernández Casas 11182, R. Morales E al. (MA 514618).

\section{Nepeta L.}

Consta de unas 200 especies que viven en Eurasia y África (Budantsev in Harley \& al., 2004: 250).

1. N. robusta Hooker fil., J. Proc. Linn. Soc., Bot. 7: $212(1864)$

Satureja robusta (Hooker fil.) Brenan, Mem. New York Bot. Garden 9: 48 (1954)

Tipo: "Hab. Cameroons Mountains, alt. 6000-8000 feet (Fl. Nov., Dec.)".

Iconografía: Fig. 11.

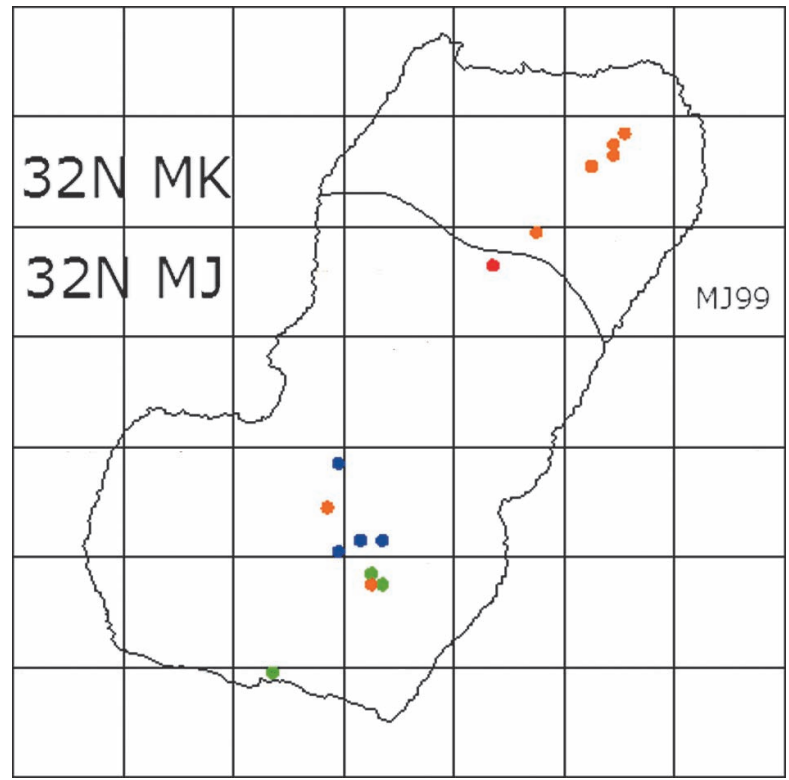

Fig. 10. Distribución en Bioko de Micromeria punctata, Nepeta ro-

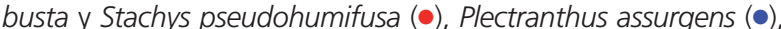
P. cataractarum (๑), P. decurrens $(\bullet)$.

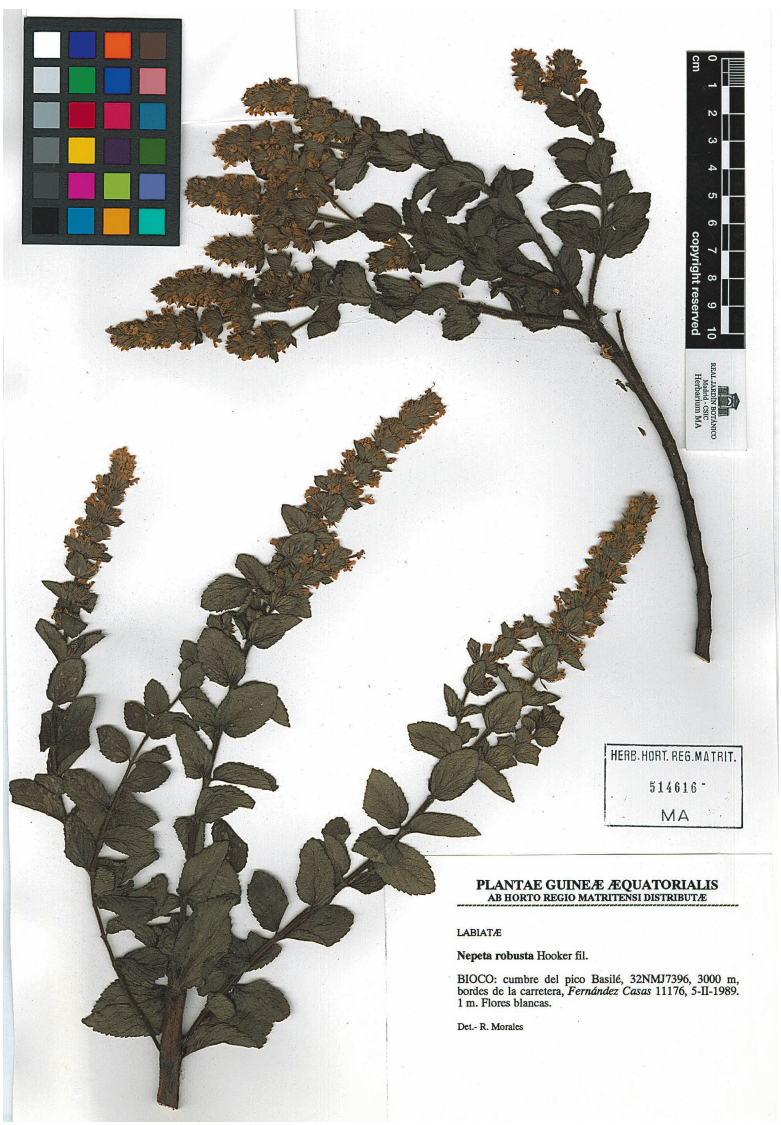

Fig. 11. Nepeta robusta (MA 514616).

Planta hasta de $1 \mathrm{~m}$, leñosa, con tallos densamente pelosos, con pelos muy cortos. Hojas 1,7-4 × 1,4-2,6 $\mathrm{cm}$, subsésiles, con pecíolo c. $2 \mathrm{~mm}$, ovadas o elípticas, dentadas, pelosas. Inflorescencia en verticilastros, a veces densos, con brácteas como las hojas, pero algo más pequeñas y bractéolas $4-6,5 \mathrm{~mm}$, de lineares a lanceoladas. Cáliz 4,5-6 mm; tubo con nervios marcados; dientes c. $2 \mathrm{~mm}, \pm$ iguales. Corola 7 $10 \mathrm{~mm}$, con labio superior c. $3 \mathrm{~mm}$, algo cóncavo, color blanco. $2 n=42$.

Bordes de carretera o entre el matorral, $3000 \mathrm{~m}$. Bioko Sur, en el pico Basilé (Fig. 10). Según Morton (1963: 467) es exclusiva de Bioko y el Monte Camerún. Exell (1973: 387, fam. 128) no la cita para Bioko. Cheek \& al. (2004: 308) tampoco la citan de Bioko, probablemente por descuido.

La pertenencia de esta especie a Nepeta es justificada claramente por Morton (1962: 260), aunque la considere incluida dentro de Satureja s.l.

\section{Material estudiado}

Bioko Sur: Pico Santa Isabel, 1-III-1947, Guinea 2703 (MA 514607). Cumbre del pico Basilé, 32NMJ7396, $3000 \mathrm{~m}$, bordes de 
la carretera, 5-II-1989, Fernández Casas 11176, R. Morales E al. (MA 514616). $1 \mathrm{~m}$. Flores blancas.

\section{Ocimum L.}

Consta de unas 65 especies que viven en los trópicos de todo el mundo (Paton in Harley \& al., 2004: 260).

1. Planta arbustiva, hasta de $2 \mathrm{~m}$; hojas hasta de $12 \mathrm{~cm} \ldots \ldots$... 3. O. gratissimum

1. Planta herbácea, hasta de 0,7 m; hojas hasta de $7 \mathrm{~cm} \ldots 2$

2. Planta pelosa; hojas lanceoladas; corola pequeña 1. O. americanum

2. Planta generalmente glabra; hojas elípticas u ovadas; corola hasta de $9 \mathrm{~mm}$

2. O. basilicum

1. O. americanum L., Cent. Pl. 1: 15 (1755)

O. canum Sims., Mag. Bot. 51: t 2452 (1823)

Tipo: "Habitat in America. Miller". Lectótipo: LINN 749.9; de América.

Descripción e iconografía: J. Berhaut (1975). Fl. ill. Sénégal 4: 206-207; R. M. Harley \& al. (2004). Labiatae in Kadereit \& Kubitzky. The families and genera of vascular plants VII: 254.

Planta herbácea, con tallos pelosos. Hojas con largos pecíolos, elípticas, dentadas. Inflorescencia en verticilastros densos. Cáliz con labio superior orbicular. Corola, pequeña, color crema.

Se han encontrado solamente citas de Bioko. Según Morton (1963: 452) es una especie muy extendida por los trópicos.

No se dan medidas en esta especie, porque no se ha visto material de herbario del territorio estudiado.

\section{Material estudiado}

Bioko: X-1841, T. Vogel 32 (Morton, 1963: 452). 1858, Barter (Mildbraed, 1922: 191).

Nombre vulgar: Orégano americano.

Usos: Es común como ornamental, medicinal y aromática (Nosti, 1955: 294).

La infusión de sus hojas se tomaban para calmar el dolor de muelas, contra la disentería y como febrífugo. Sus hojas se utilizan como condimento y se cultiva la planta como repelente de insectos. Tiene efecto emenagogo, facilitando el parto (Gómez \& Merino, 1990: 152).

2. O. basilicum L., Sp. Pl. 2: 597 (1753)

Tipo: "Habitat in India, Persia". Lectótipo: LINN 749.5 .

Descripción e iconografía: J. Berhaut (1975). Fl. ill. Sénégal 4: 202-203; J.K. Morton (1963). Fl. West Trop. Africa 2, ed. 2: 452.
Planta hasta de $0,5 \mathrm{~m}$, herbácea, aromática, con tallos glabros. Hojas 3-5,5 $\times 0,8-2 \mathrm{~cm}$, pecioladas, atenuadas en la base, elípticas o lanceoladas, en general glabras. Inflorescencia en verticilastros, con brácteas como las hojas, pero mucho más pequeñas, caedizas. Cáliz 5-7 mm, pedicelado, con 2 alas laterales en el labio superior, y dientes muy agudos. Corola hasta de $9 \mathrm{~mm}$, color blanco. $2 n=48$.

Junto a poblados, en bordes de camino. Bioko y Annobón. Según Morton (1963: 452) es una especie de origen asiático cultivada en casi todo el mundo. Exell (1973: 387) la cita para Santo Tomé.

Especie cultivada desde antiguo, de la que se conocen diferentes variedades de cultivo.

\section{Material estudiado}

Bioko Norte: Servicio Agronómico de Santa Isabel, 29-XII1946, Guinea 563, 565 (MA 514602). Bioko: 1841, Vogel 80 (Mildbraed, 1922: 191). Annobón: Ambo, in village, $10 \mathrm{ft}$ [3m, 1²4'S 53'ㄹ, pathside, 15-VII-1959, Melville E Wrigley 40 (MA 185294). Flower white. Pleasant scent. San Antonio de Palé, borde de la playa de arenas blancas, [1 $27^{\prime} 40^{\prime \prime} S 5^{\circ} 38^{\prime} 5^{\prime \prime E}$ ], 25-XI-2010, M. Fero 242 E al. (MA 800864). Herbácea.

Usos: Sus hojas se utilizan como condimento (Morales, 2001: 66).

\section{O. gratissimum L., Sp. Pl. 2: 1197 (1753)}

O. viride Willd., Enum. Pl.: 629 (1809)

Tipo: "Habitat in India". Neotipo: LINN 749.2; cultivado en Upsala, original de la India.

Descripción e iconografía: J. Berhaut (1975). Fl. ill. Sénégal 4: 208-209; E. Gómez \& L. Merino (1989). Plantas medicinales de Guinea Ecuatorial: 151.

Planta 1-2 m, subarbustiva, aromática, con tallos en general glabros. Hojas 6-19 × 2-6,5 cm, con largos pecíolos, atenuadas en la base, lanceoladas, acuminadas, dentadas, color verde más claro por el envés, en general glabras. Inflorescencia tirsoidea formada por ejes con verticilastros densos. Cáliz 5-6 mm, pedicelado, con diente superior mucho más ancho que los otros 4, los 2 laterales cortos y labio inferior con 2 más pequeños. Corola c. $4 \mathrm{~mm}$, abierta, color blanco. $2 n=40,48$.

Lugares ruderalizados, lindes de plantación de cacao, junto a caminos, a veces cultivada; 0-300 m. Bioko, Annobón y Río Muni (Fig. 6). Según Morton (1963: 452) es de distribución pantropical, probablemente de origen asiático. Se encuentra también en Santo Tomé y Príncipe (Exell, 1973:387). Según Nosti (1955: 294), era planta muy común, que se encontraba asilvestrada. 


\section{Material estudiado}

Bioko Norte: Malabo-Sampaca, Compañía Agrícola Manuel, 32NMK7413, 300 m, plantaciones de cacao, 18-VIII-1986, Carvalho 2331 (MA 514505). Subarbusto de 1-1,3 m. Flores blancas. Basakato de la Sagrada Familia, 32NMK8900, 0 m, lugares ruderalizados, 12-II-1989, Fernández Casas 11512, R. Morales E al. (MA 514626). 1,6 m. Carretera a Basilé, km 4, 32NMK7610, $180 \mathrm{~m}$, lindes en plantación de cacao, 25-II-1989, Fernández Casas 11995, R. Morales E al. (MA 514635). Subarbusto, 2 m. Bioko Sur: Balachá de Riaba, [32NMJ6875], 15-I-1947, Guinea 1543 (MA 514603). Cerca de Veiga y Avendaño, patio Drumen, 32NMJ4283, 5 m, lugares ruderalizados, 26-II-1989, Fernández Casas 12051, R. Morales $\mathcal{E}$ al. (MA 514638). Arbusto, 2 m. Bioko: X-1841, T. Vogel 4 (Morton, 1963: 452, 1.3). 1858, Barter (Mildbraed, 1922: 191). Annobón: Ambo, by our houses, [1 $\left.1^{\circ} 24^{\prime} \mathrm{S} 5^{\circ} 37^{\prime} \mathrm{E}\right], 50 \mathrm{ft}$ [15 m], 13 VII-1959, Wrigley E Melville 142 (MA 185292). Shrub like labiate. Off-white corolla. Labiate smell. Between Ambo and S. Cruz, along coastal path, $150 \mathrm{ft}$ [45 m], dry slope in open part of forest near path, 7-VIII-1959, Melville \& Wrigley 241 (MA 185291). Corolla white. Stamens yellow. Pleasant labiate smell. Bei San Pedro, gepflanzt, IX-X-1911, Mildbraed 6752 (BD) (Mildbraed, 1922: 163; Exell, 1944: 267). Río Muni: Asep, Servicio Agronómico, 4-I-1947, Nosti (Guinea 920) (MA 514821).

Nombres vulgares: Orégano del país; bojasa, malumbé (bubi); mesep (fang).

Usos: Según Nosti (1955: 294) se utiliza como ornamental, medicinal, comestible y aromática. Su infusión se bebe como té y sus hojas se comen en ensalada. Mezcladas sus hojas frescas con grasa, se obtiene una pomada eficaz contra la sarna. La infusión de sus hojas bebida sirve para cortar las hemorragias nasales y para calmar dolores de tripa. Al parecer también tienen acciones sudorífica y antipirética. Se usan aplicadas sobre la frente contra el dolor de cabeza y también en las heridas como cicatrizante. Su jugo se exprime en los ojos para aliviar la conjuntivitis (Gómez \& Merino, 2001: 103, 130). El aceite esencial mezclado con aceite de coco o de palma se unta en la piel para evitar picaduras de insectos. La decocción de sus hojas bebida calma los ataques de tos y sirve para purificar el agua de beber. También aplicada como lavativa, calma el dolor de vientre (Gómez \& Merino, 1990: 150).

\section{Platostoma P. Beauv.}

Consta de 45 especies que viven en África tropical, Asia y Australia (Paton in Harley \& al., 2004: 263).

\section{P. africanum P. Beauv., Fl. Oware 2: 61 pl. 95 fig. 2} (1818)

Tipo: "Rouyaume de Benin".

Descripción e iconografía: J. Berhaut (1975). Fl. ill. Sénégal 4: 214-215.

Planta 0,07-0,9 cm, herbácea, postrada, ascendente, con tallos en general pelosos. Hojas 1,5-7,5 × 1-3 $\mathrm{cm}$, pecioladas, atenuadas en la base, elípticas u ovadas, agudas, dentadas, \pm pelosas. Inflorescencia en verticilastros separados. Cáliz 2-3 mm, con largo pedicelo curvado hacia abajo, con labio superior redondeado y inferior de borde plano. Corola c. $2 \mathrm{~mm}$, con labio inferior alargado, color blanco, verdusco, amarillo, lila, rosado, morado pálido, azul claro o azul celeste. $2 n=14,28,42$.

Sotobosque de bosque primario o secundario bien recuperado, praderas, taludes de carretera húmedos y umbríos; 290-1335 m. Bioko y Río Muni (Figs. 4, 6). Según Morton (1963: 453) es especie que vive en toda África tropical y también en la India. Exell (1973:387) la cita para Santo Tomé.

Especie de morfología muy variable.

\section{Material estudiado}

Bioko Norte: Carretera al pico Basilé, km 3, 32NMK8307, taludes de la carretera, lugares húmedos y sombríos, 30-VII-1986, Carvalho 2156 (MA 514509). Herbácea de 20-30 cm. Flores rosadas. Dispersa. Carretera del pico Basilé, km 8, 32NMK8104, 1200 m, bosque primario, lugar sombrío, 21-VIII-1986, Carvalho 2362 (MA 533933). Herbácea, postrada. Flores entre verdes y blancas. Carretera al pico Basilé, $\mathrm{km}$ 4, 32NMK8406, $900 \mathrm{~m}$, bosque secundario bien recuperado, 13-VII-1988, Carvalho 3528 (MA 514500). Herbácea de 60-90 cm. Flores blancas. Carretera del pico Basilé, km 8-9, 32NMK8003, $1335 \mathrm{~m}$, herbazal en el borde de la pista, 5-II-1989, Fernández Casas 11231, R. Morales E al. (MA 514624). Carretera del pico Basilé, 32NMK8406, 880 m, sotobosque, 5-II-1989, Fernández Casas 11235, R. Morales E al. (MA 514615, 525878,533856$) .80 \mathrm{~cm}$. Flores color azul claro. Cerca del cruce de Bariobe, 32NMJ8596, $350 \mathrm{~m}$, taludes húmedos y sombreados de la carretera, 12-II-1989, Fernández Casas 11523, R. Morales E al. (MA 514627). Flores de color lila. Malabo-Riaba, junto al puente del km 32, 32NMJ8698, 290 m, margen de carretera, 17-II-1989, Fernández Casas 11673, R. Morales E al. (MA 514642). Flores color morado pálido. Estrada, [32NMK7707], I, Akpabla GC 11486 (Morton, 1963: 453, 4). Bioko Sur: Carretera a San Carlos, km 35, bosque, [32NMJ5795], 31-XII1946, Guinea 754 (MA 255497). Musola, praderas sobre lavas, [32NMJ5780], 13-I-1947, Guinea 1330 (MA 514649). Finca de Marcelino Puente, km 17, [32NMJ5978], 17-I-1947, Guinea 1565. Entre Moca y Riaba por el camino viejo, 32NMJ6469, 1180 m, prados, 20-II-1989, Fernández Casas 11855, R. Morales E al. Belebú Balachá, 32NMJ5376, 720 m, bosque, 28-II-1989, Fernández Casas 12115, R. Morales E al. (MA 514639). Trocha del Servicio Agronómico de Musola, [32NMJ5780], 10-I-1947, Guinea 1084 (Morton, 1963: 453, 4). Bioko: 1841, Vogel 213 (Mildbraed, 1922: 191). 1858, Barter (Mildbraed, 1922: 191). Litoral: Bata-Bome, margen del río Roara, [1 $\left.1^{\circ} 45^{\prime} \mathrm{N} 9^{\circ} 45^{\prime} \mathrm{E}\right]$, bosque primario con formaciones de Pandanus, 6-VI-1991, Carvalho 4716 (MA 597506). Herbácea que forma pequeñas colonias. Flores pequeñas color azul celeste. BataBome, praderas con gramíneas, ciperáceas, en islas arbóreas y arbustivas, 9-V-1992, Carvalho 5105 (MA 599743). Herbácea de unos $40-50 \mathrm{~cm}$. Flores pequeñas color rosado.

\section{Plectranthus L'Héritier} incl. Solenostemon y Coleus

Género que consta de unas 300 especies que viven en los trópicos del Viejo Mundo (Paton in Harley \& al., 2004: 265).

Nosti (1955: 292) cita P. esculentus N.E. Brown 
(como Coleus dazo A. Cev. \& Perrot.), cultivada en la Granja de Santa Isabel, y que produce tubérculos muy largos comestibles de sabor como la patata. También se encuentra como planta ornamental P. scutellarioides (L.) R. Br. (como Coleus verschaffeltti Lem.) cultivada según indica en los jardines de la antigua colonia como ornamental.

La cita de P. insignis Hooker fil., J. Proc. Linn. Soc., Bot. 7: 210 (1864), [Bioko: ca. $2000 \mathrm{~m}$, halbstrauchig, $5 \mathrm{~m}$ und höher, XI-1911, Mildbraed 7143 (Mildbraed, 1922: 191)], probablemente se refiera a 3. P. decurrens (Gürke) J.K. Morton.

1. Planta con tubérculos; corola hasta de $7 \mathrm{~mm}$.....

10. P. rotundifolic

1. Planta rizomatosa o herbácea, a veces perenne; corola en

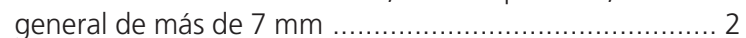

2. Hojas grandes, hasta de $35 \mathrm{~cm}$, largamente atenuadas en el pecíolo; cáliz 9-13 mm ....................... 3. P. decurrens

2. Hojas mayores hasta de $19 \mathrm{~cm}$, pecioladas o sentadas, atenuadas o cordadas; cáliz hasta de $7 \mathrm{~mm}$..................... 3

3. Hojas sentadas o con pecíolo muy corto

4. Planta rizomatosa, postrada, ascendente, hasta de 0,5 m; hojas carnosas, con pecíolo muy corto, a veces maculadas; cáliz 5,5-7 mm ................................. 9. P. punctatus

4. Planta erecta, hasta de 0,7 m; hojas en general sésiles; cáliz 5-6 mm ..................................... 6. P. inselbergi

3. Hojas pecioladas, con pecíolo a veces muy largo ............. 5

5. Planta 0,15-0,25 m, en general postrada; inflorescencia formada por 2 verticilos racemosos ....... 4. P. epilithicus

5. Planta de más talla, en general ascendente; inflorescencia en ejes de verticilastros

6. Planta subarbustiva, erguida, hasta de $2 \mathrm{~m}$, pubescente con pelos glandulares; hojas cordadas en la base

5. P. glandulosus

6. Planta herbácea, postrada o ascendente, con tallos pelosos; hojas atenuadas, a veces bruscamente ................... 7

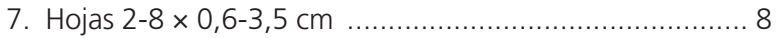

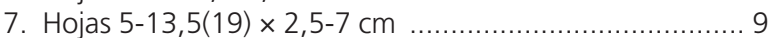

8. Planta herbácea; hojas anchamente ovadas; cáliz 4-5 mm .

Planta subleñosa; hojas elípticas; cáliz 6-7 mm

2. P. cataractarum

9. Planta hasta de 0,8 m; hojas no rugosas; inflorescencia hasta de $40 \mathrm{~cm}$, finas ................. 7. P. monostachyus

9. Planta hasta de $3 \mathrm{~m}$; hojas gruesas y rugosas; inflorescencia hasta de $25 \mathrm{~cm}$, con flores largamente pediceladas .....

8. P. occidentalis

1. P. assurgens (Baker) J.K. Morton, J. Linn. Soc., Bot. 58: 268 (1962)

Coleus assurgens Baker, Fl. Trop. Africa 5: 428 (1900)

Tipo: "Nile Land. Abyssinia: Begemeder, Schimper!".

Descripción: Baker, Fl. Trop. Africa 5: 428 (1900).

Iconografía: Fig. 12.

Planta 0,45-0,8 m, herbácea, con tallos pelosos, con pelos de células teñidas. Hojas 2-7 × 1,5-4,5 cm, pecioladas, atenuadas en la base, anchamente ovadas, dentadas, con dientes redondeados, en general pelosas. In-

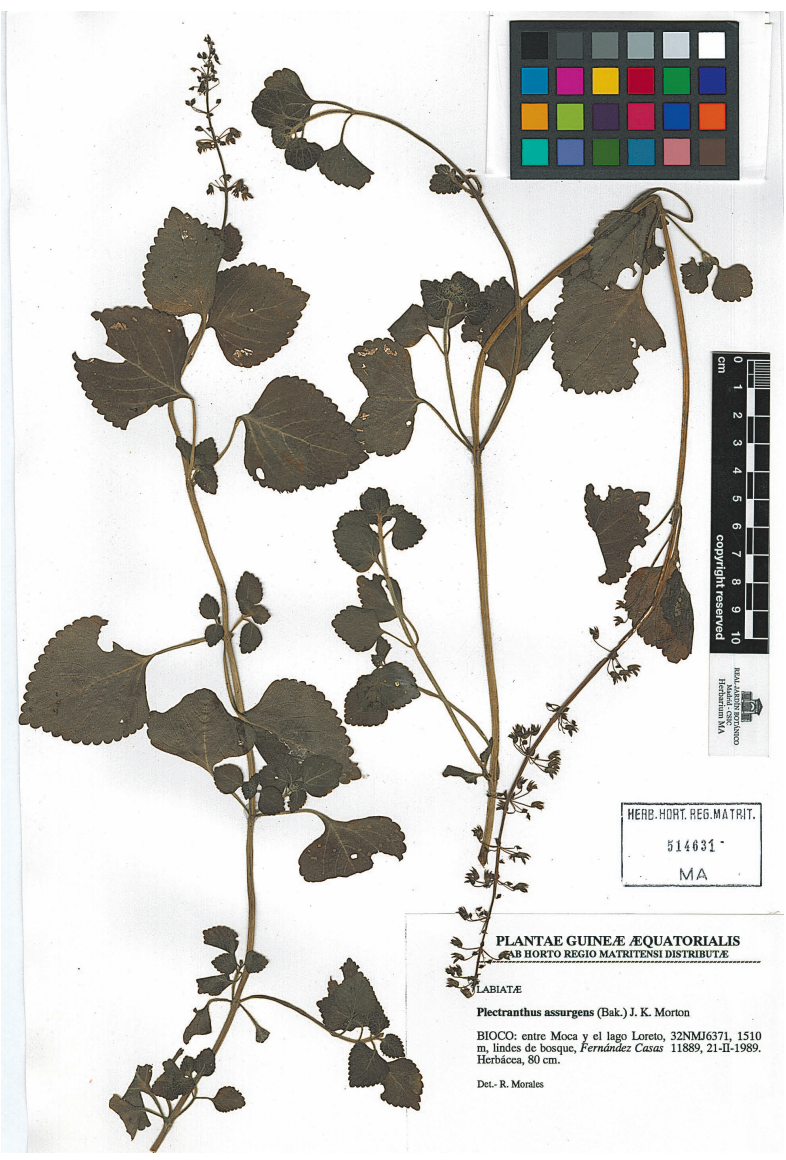

Fig. 12. Plectranthus assurgens (MA 514631).

florescencia en vertilastros con hasta 8 flores largamente pediceladas. Cáliz 4-5 mm, con diente superior más ancho y los 4 inferiores \pm iguales, curvados hacia arriba, todos de la misma longitud. Corola c. $8 \mathrm{~mm}$, con labio inferior aquillado, color violeta. $2 n=26,28$.

Lindes de bosque, praderas; 1510-1860 m. Bioko Sur (Fig. 10). Según Morton (1963: 460) se encuentra también en Nigeria, Camerún y en el E de África.

\section{Material estudiado}

Bioko Sur: Finca de Marcelino Puente, km 17 de la carretera de Musola a Moca, [32NMJ5978], 17-I-1947, Guinea 1566, 1568 (MA 514817). Subida Pico Serrano [pico San Joaquín] [32NMJ6171], 25-I-1947, Guinea 1971, 1989 (MA 513102). Entre Moca y el lago Loreto, 32NMJ6371, 1510 m, lindes de bosque, 21II-1989, Fernández Casas 11889, R. Morales E al. (MA 514631). Herbácea, $80 \mathrm{~cm}$. Entre Moca y el lago Biaó, 32NMJ5970, $1860 \mathrm{~m}$, praderas, 22-II-1989, Fernández Casas 11945, R. Morales E al. (MA 514633). $75 \mathrm{~cm}$. Flores color violeta. X, Monod 10427 (Morton, 1963: 460, 14.3).

2. P. cataractarum B.J. Pollard in Pollard \& Paton, Kew Bull. 56: 976 (2001)

Solenostemon decumbens sensu Morales, Fontqueria 
36: 290 (1993); 39: 16 (1994); sensu Aedo, Tellería \& Velayos, Bases documentales para la flora de Guinea Ecuatorial: 225 (1999) non (Hooker fil.) Baker [Plectranthus decumbens Hooker fil.]

Tipo: "Mount Cameroon, forest above oil palm plantation, hunters path to lake Njonji at side of seasonal watercourse, 4 ${ }^{\circ}{ }^{\prime} \mathrm{N} 8^{\circ} 59^{\prime} \mathrm{E}, 300 \mathrm{~m}, 25$-XI-1993, Cheek 5563 \& al., holotipo K, isotipo MA 789767, MO, SCA, WAG, YA”.

Descripción e iconografía: Kew Bull. 56: 976, 978 (2001).

Planta 0,25-0,5 m, herbácea subleñosa, postrada o ascendente, con tallos pelosos. Hojas 2-8 × 0,6-2,5 $\mathrm{cm}$, pecioladas, atenuadas en la base, elípticas o lanceoladas, agudas, con dientes suaves en la mitad superior, con pelos dispersos. Inflorescencia en verticilastros con 8 flores cada uno, largamente pediceladas. Cáliz 6-7 $\mathrm{mm}$, peloso, con diente superior ancho, los 2 laterales triangulares, más pequeños, y con labio inferiores ancho, a veces escotado, más largo. Corola 8-9 $\mathrm{mm}$, con tubo curvado hacia abajo, y lóbulo inferior aquillado, dispuesto hacia arriba, color lila.

Lugares muy húmedos, en piedras del lecho del río, o en praderíos; 50-1280 m. Bioko Sur (Fig. 10). Vive también en Camerún, de donde procede el material tipo (Pollard, 2001: 977).

\section{Material estudiado}

Bioko Sur: Ureka, [32NMJ5359], 16-II-1947, Guinea 2496 (MA 514609). Moca-cascadas del río Iladyi, márgenes del río, 32NMJ6367, $1280 \mathrm{~m}$, entre las piedras del lecho del río, 18-I-1989, Carvalho 3889 (MA 514513). Herbácea postrada o ascendente. Flores lilas. Frecuentes en grupos reducidos. Moca, camino de Ureca, al final de las praderas, 32NMJ6268, $1260 \mathrm{~m}$, praderas con rodales de bosque, 19-II-1989, Fernández Casas 11745, R. Morales É al. (K.)

3. P. decurrens (Gürke) J.K. Morton, J. Linn. Soc., Bot. 58: 267 (1962)

Coleus decurrens Gürke, Bot. Jahrb. Syst. 19: 215 (1894)

C. elatus Baker, Fl. Trop. Africa 5: 427 (1900)

Tipo: "Kamerun: am Bache in Buea, $950 \mathrm{~m}$ (Preuss n. 948 -21. Sept. 1891, blühend und fruchtend)".

Descripción: Bot. Jahrb. Syst. 19: 215 (1894).

Iconografía: Fig. 13.

Planta 1-2,3 m, herbácea subarbustiva, con tallos afelpados. Hojas $12-35 \times 3,5-10 \mathrm{~cm}$, pecioladas, atenuadas en la base, elípticas, dentadas. Inflorescencia $12-30 \mathrm{~cm}$, dividida, formada por ejes de verticilastros con hasta 8 flores pediceladas. Cáliz $9-13 \mathrm{~mm}$, peloso, con 2 dientes laterales cortos y 2 inferiores muy largos. Corola $10-15 \mathrm{~mm}$, color rosado por fuera y amarillo por dentro.
Bosques primario o secundario, en claros con helechos arborescentes, junto a arroyos, en lugares sombríos, o en taludes de carretera; 670-1750. Bioko y Río Muni (Figs. 4, 10). Según Morton (1963: 464) se encuentra en Nigeria, Camerún y Gabón.

\section{Material estudiado}

Bioko Norte: Carretera del pico Basilé, 32NMK8508, 670 m, bosquetes secundarios, 9-VII-1986, Fernández Casas 10282 \& al. MA 525879, 533855). 1,6 m. Flores amarillas. Carretera al pico Basilé, $\mathrm{km} \mathrm{4,} \mathrm{32NMK8407,} 750 \mathrm{~m}$, bosque primario, borde de un arroyo, 29-VII-1986, Carvalho 2129 (MA 525875, 533859). Arbusto 1-2 m. Flores amarillas. Carretera al pico Basilé, km 6-7, 32NMK8205, 1050 m, taludes de la carretera, 25-IX-1986, Carvalho 2503 (MA 514503). Herbácea de 1,3 m. Dispersa. Carretera del pico Basilé, km 4-5, 32NMK8406, $900 \mathrm{~m}$, bosque secundario con Pycnanthus angolensis, 10-VIII-1989, Carvalho 4057 (MA 514522). Herbácea $1,5 \mathrm{~m}$. Flores rosadas por fuera y amarillentas por dentro. Carretera del pico Basilé, km 16-17, 32NMJ7799, $1750 \mathrm{~m}$, bosque ralo con pradera, 10-IX-1990, Carvalho 4477 (MA 533937). Subarbusto $2,3 \mathrm{~m}$. Flores amarillas muy vistosas. Ramas florales áfilas. Bioko Sur: Moca, camino de Ureca, 32NMJ6267, $1080 \mathrm{~m}$, claros de bosque denso con helechos arborescentes, 19II-1989, Fernández Casas 11786, R. Morales É al. (MA 525877). 1,3 m. Flores amarillas. Moca, camino de Ureca, 32NMJ6267, $1080 \mathrm{~m}$, claros de bosque denso con helechos arborescentes, 19-

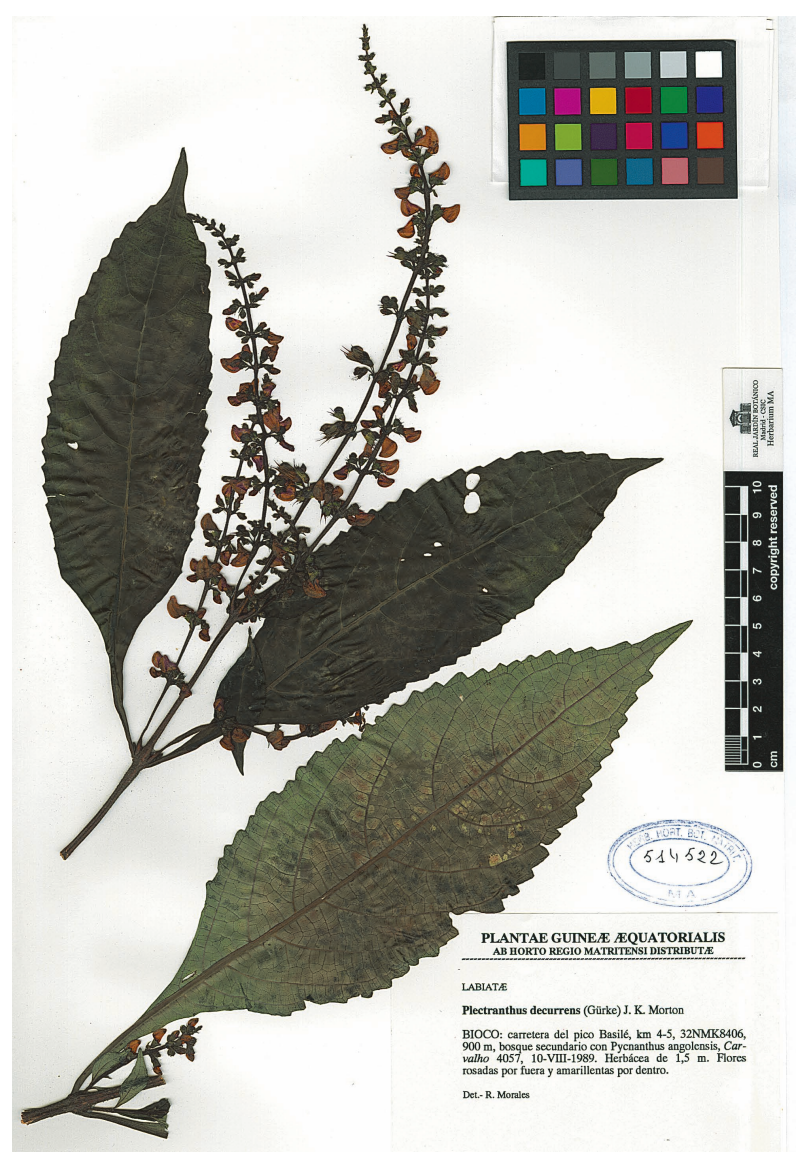

Fig. 13. Plectranthus decurrens (MA 514522). 
II-1989, Fernández Casas 11790, R. Morales E al. 1,5 m. Flores azules. Riuché - gran caldera de Luba, más de medio camino, 32NMJ5874, bosque primario denso y sombrío con Ficus de gran porte, 23-III-1989, Carvalho 3837 (MA 514510). Herbácea de 1,2 m. Flor amarilla. Rara. Bioko: 600-800 m, nicht selten, VIII1911, Mildbraed 6255 (Mildbraed, 1922: 190). X, Mann 584 (Morton, 1963: 460, 14.14). Centro Sur: Eviam, carretera forestal de Bata a Niefang, $1^{\circ} 44^{\prime} \mathrm{N} 10^{\circ} 10^{\prime} \mathrm{E}, 4-\mathrm{V}-2000$, R. Pérez Viso 2634 (MA 833154).

4. P. epilithicus B.J. Pollard, Kew Bull. 60(1): 145 (2005)

Solenostemon repens (Gürke) J.K. Morton, J. Linn. Soc., Bot. 58: 272 (1962)

Coleus repens Gürke, Bot. Jahrb. Syst. 19: 213 (1894) non Plectranthus repens Wallich, Pl. Asiat. Rar. 2: 17 (1830)

Coleus carnosus A. Chev., J. Bot. (Morot), sér. 2, 2: 125

(1909) non Coleus carnosus Hassk., Flora 25(2, Beibl.): 25 (1842)

Tipo: "Kamerun: Im Urwald westlich von Buea, an Steinen und auch epiphytisch, 1200 m (Preuss n. 949 -21. Sept. 1891, blühend und fruchtend)". Holótipo: "B, presumed †; Cameroon, Mt Kupe, Nyasoso, natu-

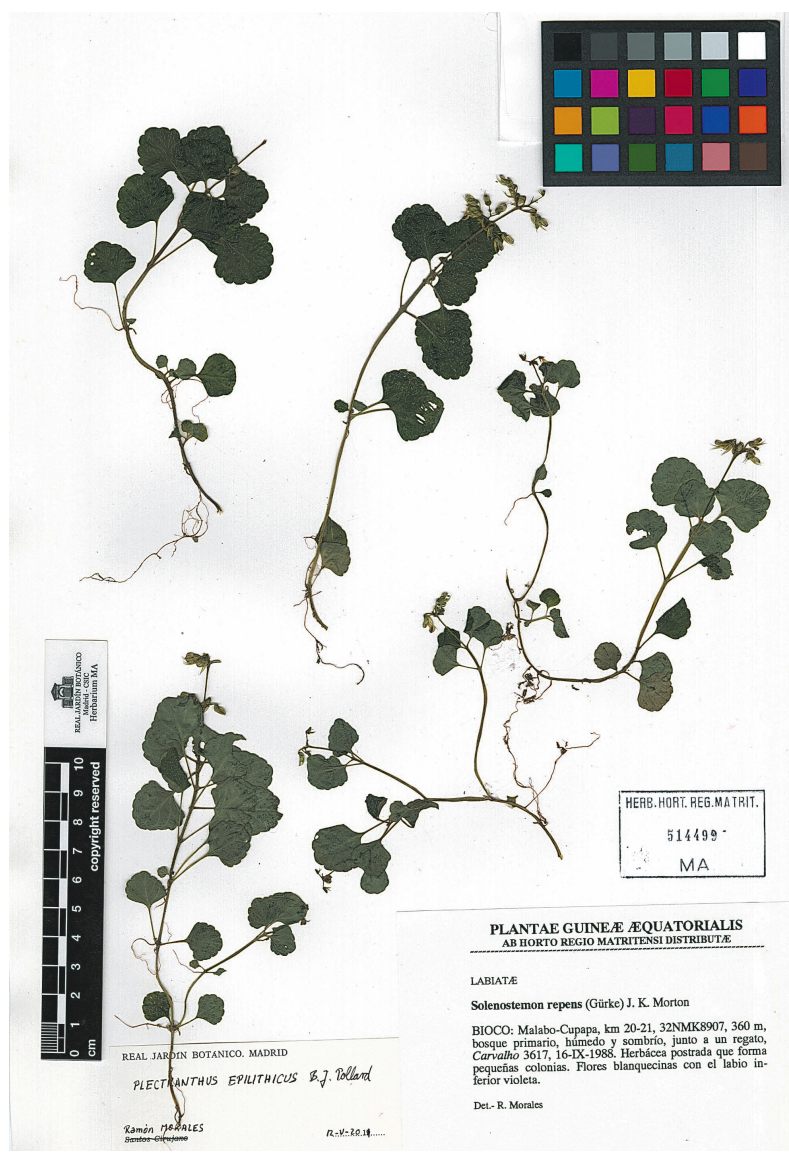

Fig. 14. Plectranthus epilithicus (MA 514499).

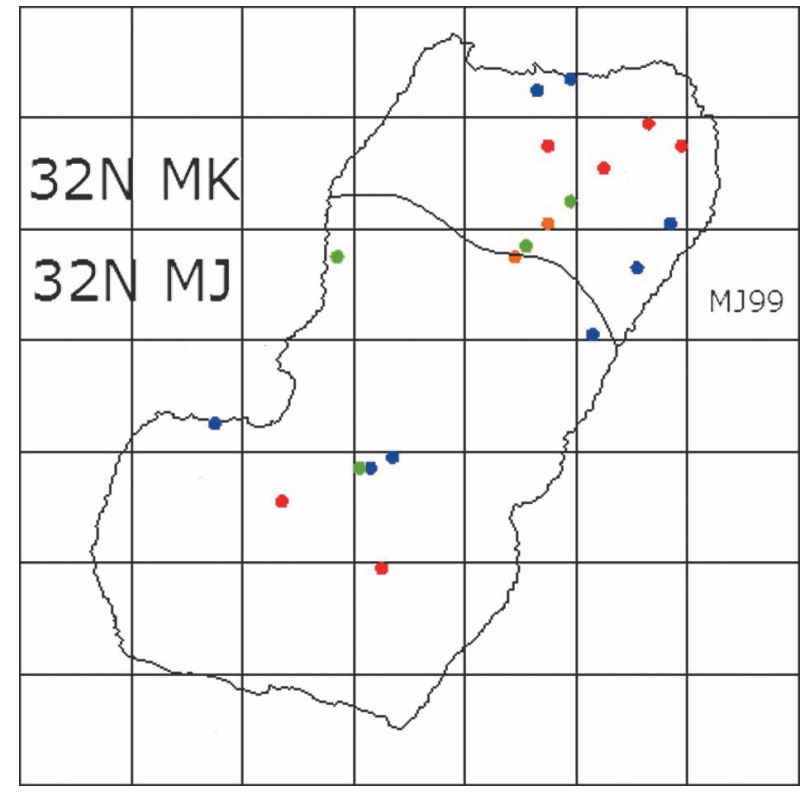

Fig. 15. Distribución en Bioko de Plectranthus epilithicus (•), $P$. monostachyus $(\bullet)$, P. occidentalis $(\bullet), P$. punctatus $(\bullet)$.

re trail above de Government High School, Pollard 83, neotype K!, isoneotypes KUPE!, WAG! YA!" (Pollard, 2005: 145).

Descripción: Bot. Jahrb. Syst. 19: 214 (1894).

Iconografía: C. Aedo \& al. (2001). Botánica y botánicos en Guinea Ecuatorial: 212 fig. 12. Fig. 14.

Planta 0,15-0,25 m, herbácea, postrada, ascendente, con tallos pelosos. Hojas 1,3-4 × 0,9-3 cm, carnosas, largamente pecioladas, atenuadas en la base, anchamente ovadas u orbiculares, con dientes amplios y pocos marcados, con pelos dispersos y muy largos, blanquecinos. Inflorescencia formada por 2 verticilos racemosos, con hasta 8 flores cada uno. Cáliz 6-7 mm, acrescente, pedicelado, con labio superior orbicular, curvado hacia arriba, 2 dientes laterales y 2 largos dientes inferiores muy finos de $4 \mathrm{~mm}$. Corola c. $12 \mathrm{~mm}$, color crema, con labio inferior aquillado, color violeta. $2 n=30$.

Bosques primarios, junto a riachuelos, en ambiente sombrío y húmedo, sobre troncos caídos o piedras, formando pequeños tapices; 360-1050 m. Bioko y Río Muni (Figs. 4, 15). Según Morton (1963: 452) se encuentra en el W de África, y según Pollard (2005: 145), en Guinea, Sierra Leona, Liberia, Costa de Marfil, Ghana, Camerún y Gabón.

\section{Material estudiado}

Bioko Norte: 600 bis 800 m, VIII-1911, Mildbraed 6265 (Mildbraed, 1922: 190). Monte Balea, NE, camino de Laka, [32NMK8609], 28-XII-1946, Guinea 377 (MA 254907), Guinea 491 (MA 254906), Guinea 492. Carretera del pico Basilé, km 3-4, 
32NMK8205, $1000 \mathrm{~m}$, bosque primario, junto a un regato, 30-VII1986, Carvalho 2157 (MA 533932). Postrada, forma pequeños tapices sobre el tronco de árboles caídos. Flores color violeta. Cerca de Basilé, finca Eloy Estrada, 32NMK7707, 550 m, bosque primario, sobre una piedra, en lugar húmedo y sombrío, 17-IX-1986, Carvalho 2470 (MA 533934). Herbácea, postrada. Flores color blanco vinoso. Malabo-Cupapa, km 20-21, 32NMK8907, 360 m, bosque primario, húmedo y sombrío, junto a un regato, 16-IX-1988, Carvalho 3617 (MA 514499). Herbácea postrada que forma pequeñas colonias. Flores blanquecinas con el labio inferior violeta. Bioko Sur: Belebú Balachá, 32NMJ5375, 1050 m, bosque denso, 28-II-1989, Fernández Casas 12158, R. Morales E al. (MA 514640). Flores azules. Moka, [32NMJ6269], XII, Boughey 75 (Morton, 1963: 463, 17.1). Centro Sur: Bata-Niefang, km 35, entre los ríos Sama y Comayá, [149’N 105'E], bosque primario, 7-III-1995, Carvalho 5833 (MA 609819). Herbácea postrada ascendente formando pequeños grupos sobre las rocas junto a un riachuelo, en ambiente sombrío y húmedo.

5. P. glandulosus Hooker fil., J. Proc. Linn. Soc., Bot. 6: 17 (1861)

P. bylopbilus Gürke, Bot. Jahrb. Syst. 19: 203 (1894)

Tipo: "Hab. In Clarence Peak, alt. 7000 ped. (fl. April)".

Descripción: Bot. Jahrb. Syst. 19: 203 (1894).

Iconografía: Figs. 16, 17.

Planta 0,6-2 m, herbácea, que forma pequeñas colonias, aromática, con tallos pelosos, con pelos muy pequeños. Hojas 7-17 × 3,5-10 cm, con largos pecíolos, cordadas en la base, ovadas, agudas, irregularmente aserradas, pelosa sobre todo en los nervios y pecíolo. Inflorescencia dividida con ejes de verticilastros pedunculados y flores con largos pecíolos, con brácteas caedizas. Cáliz 6-7 mm, acrescente, con dientes \pm iguales, glanduloso. Corola $12-15 \mathrm{~mm}$, con tubo doblado hacia abajo y labio inferior aquillado, dispuesto hacia arriba, color azul o violeta. $2 n=28,26$.

Bosque primario, praderas arboladas, lindes, taludes de carretera; 920-2000 m. Bioko (Fig. 18). Según Morton (1963: 460) se encuentra también en Mali, Guinea, Nigeria y Camerún.

\section{Material estudiado}

Bioko Norte: Clarence Peak, 2100 m, Mann s.n. (Hooker, 1862 17). $2100 \mathrm{~m}, \mathrm{X}-\mathrm{XI}-1911$, Mildbraed (Mildbraed, 1922: 191). Carretera del pico Basilé, 32NMJ7799, 2000 m, márgenes de la pista, 9-VII-1986, Fernández Casas 10296 E al. (MA 516990, 533850). $1,8 \mathrm{~m}$. Flores azules. Olor muy fuerte a menta. Carretera del pico Basilé, km 4-5, 32NMK8406, $920 \mathrm{~m}$, bosque primario, 21-VIII1986, Carvalho 2359. Herbácea 0,6-0,8 m. Flores color violeta. Carretera al pico Basilé, km 17-18, 32NMK7801, 1750 m, taludes de la carretera, 8-X-1986, Carvalho 2540 (MA 525876, 533860). Herbácea de $2 \mathrm{~m}$. Flores azules, aromáticas. Forma pequeñas colonias dispersas. Pico Basilé, cumbre de la caldera de Bonyoma, 32NMJ7399, $2000 \mathrm{~m}$, praderas con árboles y arbustos cubiertos de líquenes, 16-XI-1988, Carvalho 3714 (MA 514512). Herbácea de 1-1,3 m. Flores azuladas, ligeramente aromáticas. Pico Santa Isabel, III-1947, Guinea 2966 (Morton, 1963: 460, 14.10). Bioko Sur: Grasland Moka, XI-1911, Mildbraed 7082 (Mildbraed, 1922: 191).
Moka [32NMJ6269], 1939, Lope del Val (MA 500437). Finca de Marcelino Puente, km 17 de Musola, [32NMJ5978], 20-I-1947, Guinea 1759 (MA 514606). Subida al pico Serrano [pico San Joaquín], [32NMJ6171], 25-I-1947, Guinea 2025, 2026 (MA 255500). Corola azul celeste. Entre Moca y el lago Biaó, borde del cráter, 32NMJ5870, 1950 m, linde de bosque, 22-II-1989, Fernández Casas 11956, R. Morales \& al. (MA 514634). Bioko: Mann 318 (Morton, 1963: 460, 14.10). Monod 10429 (Morton, 1963: 460, 14.10). Boughey 11, 178 (Morton, 1963: 460, 14.10).

6. P. inselbergi B.J. Pollard \& A.J. Paton, Kew Bull. 61: 225 (2006)

Tipo: "Equatorial Guinea, Dalle Rocheuse (inselberg), $3 \mathrm{~km} \mathrm{~S}$ of Asok, $1^{\circ} 27^{\prime} \mathrm{N}, 1^{\circ} 20^{\prime} \mathrm{E}, 640 \mathrm{~m}, 13 \mathrm{Jan}$. 1999, LeJoly 99/282, holotypus BRLU!; isotypus: K!”.

Descripción e iconografía: Kew Bull. 61: 225-226 (2006).

Planta 0,4-0,7 m, herbácea, ascendente, con tallos pelosos. Hojas 1,2-4 × 0,7-1,4 cm, sentadas, elípticas, glabras. Inflorescencia en verticilastros con flores pediceladas. Cáliz 5-6 mm, con diente superior ancho y sobresaliente, el inferior escotado, curvados hacia arriba, y los 2 laterales más cortos. Corola c. $15 \mathrm{~mm}$,

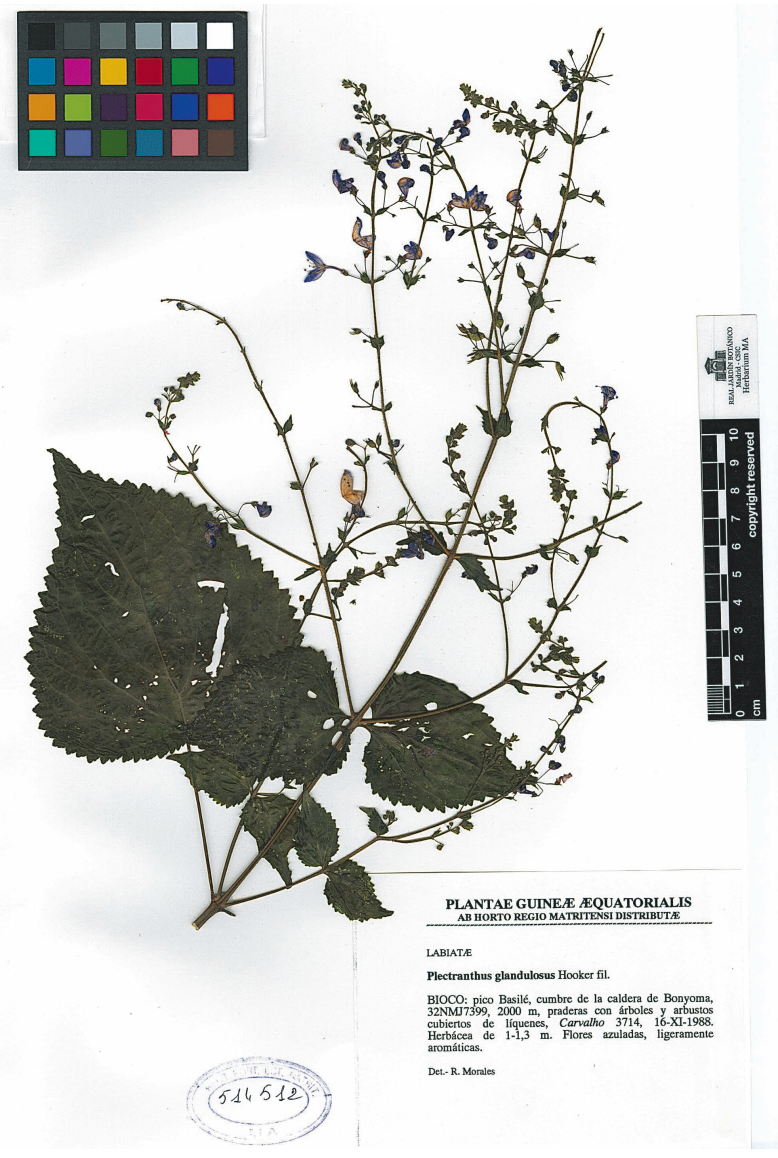

Fig. 16. Plectranthus glandulosus (MA 514512). 
con tubo doblado hacia abajo y lóbulo inferior aquillado, color violeta.

Montes isla o junto a ellos; 630-750 m. Río Muni (Fig. 4). Se encuentra también en Gabón.

\section{Material estudiado}

Wele-Nzas: Cucumancoc, [1¹8'N 1050'E], VII-1945, Guinea 380 (MA 514610). Inselberg of Mungum, 45 minutes walk from the village of Kukumancoc, $1^{\circ} 19^{\prime} \mathrm{N} 10^{\circ} 49^{\prime} \mathrm{E}, 750 \mathrm{~m}, 24-\mathrm{V}-2002$, Parmentier 3317 (BRLU) (Pollard \& al., 2006: 227). Inselberg $\mathrm{N}^{\circ}$ 3, S of Mongomo, $20 \mathrm{~km} \mathrm{~S}$ of the end of the asphalt road, $660 \mathrm{~m}$, 19-III-1998, Porembski, Biedinger \& Nguema 3569 (BRLU) (Pollard \& al., 2006: 227). Inselberg $N^{\circ} 4, S$ of Mongomo, Dumo, 750 m, 19-III-1998, Porembski, Biedinger E Nguema 3577 (BRLU) (Pollard \& al., 2006: 227). Inselberg of Dumu, near the village of Dumu, 1 ${ }^{\circ} 22^{\prime} \mathrm{N} 11^{\circ} 19^{\prime} \mathrm{E}, 700 \mathrm{~m}$, 3-VI-2002, Parmentier E Esono 3585 (BRLU, K) (Pollard \& al., 2006: 227). Inselberg Asoc, $1^{\circ} 31$ 'N 11'18'E, 17-I-1998, Obama E LeJoly 488, (BRLU) (Pollard \& al., 2006: 227). Dalle Rocheuse $3 \mathrm{~km} \mathrm{~S}$ of Asoc, $1^{\circ} 27^{\prime} \mathrm{N} 11^{\circ} 20^{\prime} \mathrm{E}, 640$ m, 13-I-1999, LeJoly 99/282 (holotype: BRLU; isotype: K) (Pollard \& al., 2006: 227). Inselberg of Asoc, at the side of the road near the village of Asoc, $1^{\circ} 17^{\prime} \mathrm{N} 11^{\circ} 20^{\prime} \mathrm{E}, 630 \mathrm{~m}, 5-\mathrm{VI}-2002$, Parmentier E Esono 3598 (BRLU, K) (Pollard \& al., 2006: 227). Inselberg of Mfui, $50 \mathrm{~km}$ E of Anisok, 152'N 1059'E, 15-I-1998, Obama E LeJoly 365 (BRLU) (Pollard \& al., 2006: 227).

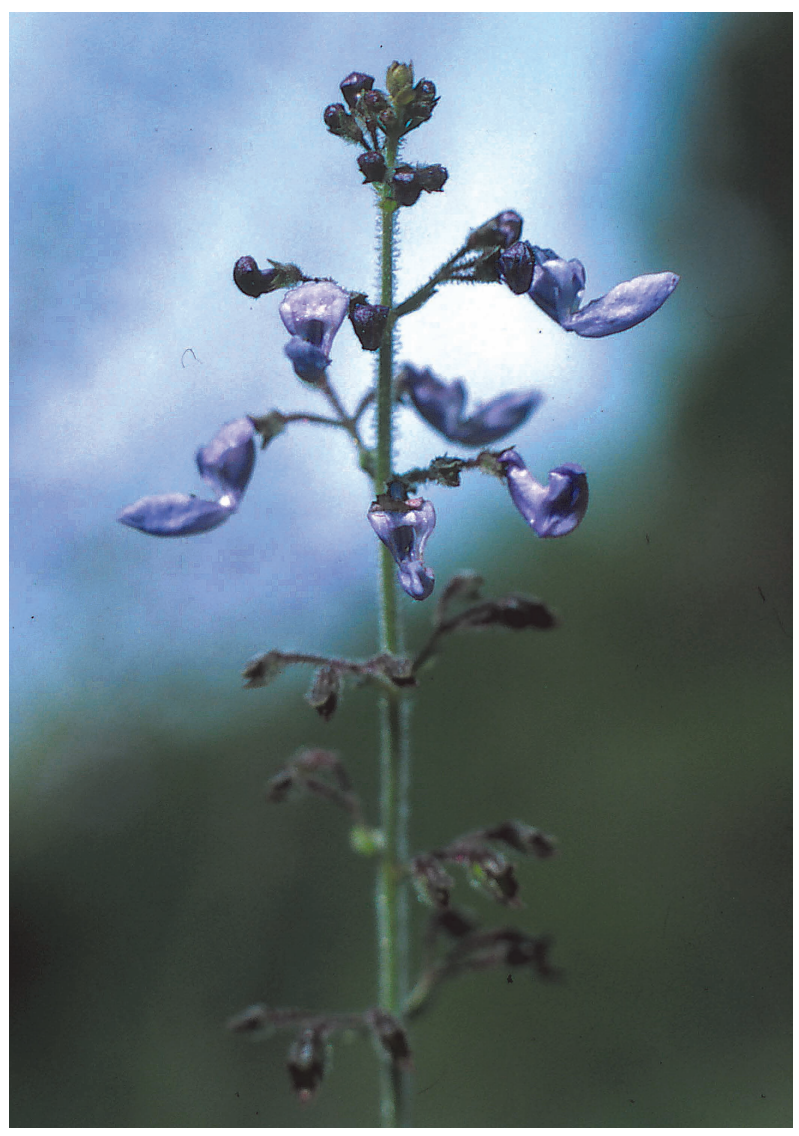

Fig. 17. Plectranthus glandulosus, subida al pico Basilé, 5-II1989, R. Morales.

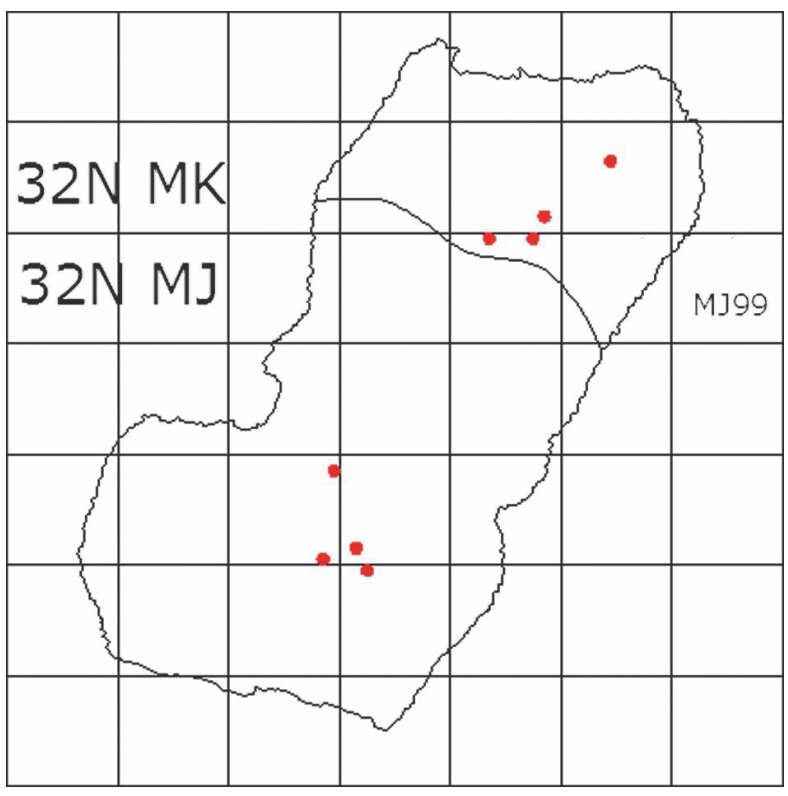

Fig. 18. Distribución en Bioko de Plectranthus glandulosus.

7. P. monostachyus (P. Beauv.) B. J.Pollard in Pollard \& Paton, Kew Bull. 56: 980 (2001) subsp. monostachyus

Ocimum monostachyum P. Beauv., Fl. Oware 2: 60 tab. 95 fig. 1 (1818)

Solenostemon monostachyus (P. Beauv.) Briquet in Engler \& Prantl, Nat. Pflanzenfam. 5, 3A: 359 (1897) subsp. monostachyus

S. ocymoides Schum. \& Thonn., Beskr. Guin. Pl.: 271 (1827)

Tipo: "Royaume de Benin".

Descripción e iconografía: J. Berhaut (1975). Fl. ill. Sénégal 4: 230-231; J.K. Morton (1963). Fl. West Trop. Africa 2, ed. 2: 464 (como Solenostemon monostachyus).

Planta 0,25-0,8 m, herbácea, postrada, ascendente, con tallos pelosos. Hojas 5,5-13,5(19) × 3,5-7 cm, pecioladas, atenuadas truncadas, anchamente ovadas, con dientes \pm marcados, pelosas sobre todo en los nervios y pecíolo. Inflorescencia hasta de $35 \mathrm{~cm}$, terminal, con veticilastros de flores pediceladas. Cáliz 4-6 $\mathrm{mm}$, acrescente, con diente superior orbicular, sobresaliente, 2 laterales pequeños e inferior ancho y con 2 mucrones. Corola 7-15 mm, color azul, violeta, rosado o malva. $2 n=14$.

Bosques primario o secundario, en claros, lindes, plantaciones de cacao, praderas, a veces con helechos; 5-760 m. Bioko, Annobón y Río Muni (Figs. 4, 15). Según Morton (1963: 452) vive en todo el W de África. Exell (1973: 387) la cita para Santo Tomé y Príncipe. 


\section{Material estudiado}

Bioko Norte: Servicio Agronómico de Santa Isabel, [32NMK7412], 25-XII-1946, Guinea 188 (MA 514612). Basakato del Este, [32NMK8800], 2-VI-1984, S. Castroviejo 9082b (MA 713780). Malabo-Cupapa, km 5-6, 32NMK7913, 40 m, plantaciones de cacao, 3-IX-1989, Carvalho 4083 (MA 514521). Herbácea de 30-60 cm. Flores rosadas. Frecuente y abundante. Cerca del cruce a Bariobé, 32NMJ8596, 350 m, linde de bosque, 12-II-1989, Fernández Casas 11533, R. Morales E al. (MA 514628). 50 cm. Flores color violeta. Bioko Sur: Luba-Riaba, cerca del puerto de Musola, 32NMJ6178, $730 \mathrm{~m}$, claros de bosque secundario, 29-VI1986, Fernández Casas 10078 \& al. (MA 516985). Herbácea. Flores azules. Riaba, puente sobre el río Cope, 32NMJ8190, 280 m, bosque primario, 22-VII-1986, Carvalho 2077 (MA 514520). 40-80 $\mathrm{cm}$. Flores azuladas. Luba-Veiga y Avendaño, en el límite entre Batete y Luba, 32NMJ4783, 5 m, márgenes de la carretera, 26-II1989, Fernández Casas 12019, R. Morales Es al. Luba-Riaba, a 4-5 $\mathrm{km}$ del cruce de Moca, 32NMJ6379, $760 \mathrm{~m}$, comunidad natural de gramíneas con helechos y ortigas, 5-VIII-1990, Carvalho 4445 (MA 533935). Herbácea, 40-80 cm. Flores color azulado. Bioko: Mann 404 (Morton, 1963: 465, 17.11). 1858, Barter (Mildbraed, 1922: 191). Annobón: Weg zum Q. [uioveo], 450 m, Bananenpflanzung, IX-X-1911, Mildbraed 6539 (BD) (Mildbraed, 1922: 163; Exell, 1944: 267). Borde del lago A Pot, 125'21”S 5³7’48”E, 280 m, sendero que rodea el lago, 23-XI-2010, Velayos 11563 \& al. (MA 831228). Anganchi, $1^{\circ} 26{ }^{\prime} 3$ "S 5 39 '5" E, $50 \mathrm{~m}$, bosque secundario con Elaeis, 27-XI-2010, Aedo 18064 E al. (MA 831281). Herbácea 0,6 m. Flor blanca. Litoral: Etembué costa, entre Río Benito y Cabo San Juan, [1¹7’N 9²5’E], 12-VIII-1945, Guinea 326 (MA 514823). Bata-Asonga, pradera frente a las caracolas de Cooperación Española, [1 ${ }^{\circ} 51^{\prime} \mathrm{N} 9^{\circ} 45^{\prime} \mathrm{E}$ ], 18-V-1991, Carvalho 4680 (MA 597451). Planta herbácea más o menos postrada, inflorescencias con innumerables flores azules. Aquí y allí en pequeñas colonias. Bata-Sendje, carretera km 40, junto al puente sobre el río Benito, [1³2’N 948'E], 30-V-1993, Carvalho 5318 (MA 598218). Herbácea postrada ascendente, inflorescencias terminales largas con flores color malva. Rara no local. Centro Sur: Evinayong, [1 $27^{\circ} \mathrm{N}$ 10³4'E], VI-1945, Guinea 341, (MA 514611). Evinayong, Servicio Agronómico, [1²7’'N 10³4'E], VI-1945, Guinea 472 (MA 514818). Wele-Nzas: Cerro cúpula de Asoc, [1 $\left.{ }^{\circ} 18^{\prime} \mathrm{N} 11^{\circ} 20^{\prime} \mathrm{E}\right]$, VII-1945, Guinea 2 (MA 513548, 514822).

Nombre vulgar: Esukuluku ikai (fang).

Usos: El jugo de sus hojas se aplica en fricciones contra la sarna. Sus hojas se utilizan aplicadas contra la mordedura de serpiente. La infusión es digestiva y para el dolor de tripa (Gómez \& Merino, 1990: 152).

8. P. occidentalis B.J. Pollard, Kew Bull. 60(1): 146 (2005)

Solenostemon mannii (Hooker fil.) Baker, Fl. Trop. Africa 5: 422 (1900)

Coleus mannii Hooker fil., J. Proc. Linn. Soc., Bot. 7 : 211 (1864)

Solenostemon cymosus Baker, Fl. Trop. Africa 5: 422 (1900)

P. cymosus Baker, J. Linn. Soc., Bot. 21: 434 (1886) non P. mannii Baker, Fl. Trop. Africa 5(3): 408 (1900)

Tipo: "Mt Cameroon, Mann 1967, holotypus, K!" (Pollard, 2005: 146).

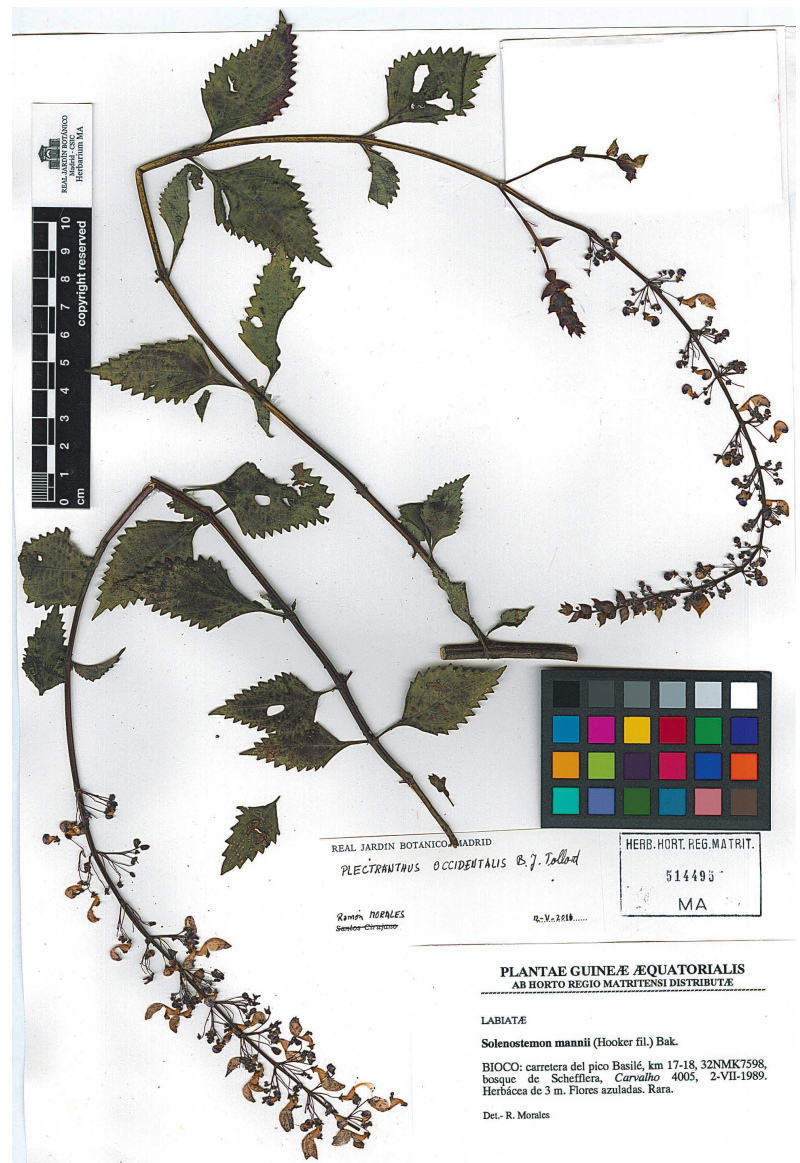

Fig. 19. Plectranthus occidentalis (MA 514495).

Iconografía: C. Aedo \& al. (2001). Botánica y botánicos en Guinea Ecuatorial: 215 fig. 19. Fig. 19.

Planta 2-3 m, herbácea, postrada, ascendente o epífita, con tallos glabros o dispersamente pelosos. Hojas $5-13 \times 2,5-6 \mathrm{~cm}$, pecioladas, atenuadas en la base, ovadas o rómbicas, agudas, dentadas, con dientes simétricos, con pelos muy pequeños, con envés color vino. Inflorescencia $16-22 \mathrm{~cm}$, en verticilastros racemosos, con brácteas c. 1,2 cm, caedizas. Cáliz 2,5 mm en la antesis, 4-5 mm, con dos labios bien diferenciados y dos dientes laterales muy pequeños, con pedicelos muy largos acrescente. Corola $9-12 \mathrm{~mm}$, con tubo curvado hacia abajo, con lóbulo central del labio inferior mucho más largo y aquillado, color azulado o violáceo. $2 n=28$.

Bosque primario o secundario, con arbustos y bejucos, bosque de Schefflera; 650-1500 m. Bioko y Río Muni (Figs. 4, 15). Según Morton (1963: 464) se encuentra en Sierra Leona, Liberia, Ghana, Nigeria y Camerún. Según Pollard (2005: 146), vive también en la República Centroafricana, Gabón, Congo y Sudán. 


\section{Material estudiado}

Bioko Norte: Basakato, [32NMJ5897], 18-III-1939, Lope del Val (MA 705248). Carretera al pico Basilé, km 13-14, 32NMK7902, 1500 m, en bosque primario, 11-XI-1986, Carvalho 2676 (MA 516992). Epífita sobre troncos de árboles a $4-5 \mathrm{~m}$ de altura. Flores violáceas. Carretera del pico Basilé, km 17-18, 32NMJ7598, bosque de Schefflera, 2-VII-1989, Carvalho 4005 (MA 514495). Herbácea de $3 \mathrm{~m}$. Flores azuladas. Rara. Malabo-pico Basilé, carretera al pico, km 18-19, bosque primario, 30-VI-1990, Carvalho 4516 (MA 514519). Planta herbacea postrada. Flores azuladas. Bioko Sur: Malabo-Moca, km 58-59, 32NMJ6078, 650 m, bosque secundario con muchos arbustos y bejucos, 30-X-1989, Carvalho 4150 (MA 514526). Herbácea postrada o ascendente, de $2 \mathrm{~m}$. Envés foliar color vino. Flores azules. Rara. Bioko: Boughey s.n. (Morton, 1963: 464, 17.7). Centro-Sur: Mafanché, entre Evinayong y Nsoc, 11-12VII-1945, Guinea 219 (MA 514601), Guinea 221 (MA 514600). Wele-Nzas: Cerro cúpula de Cucumancoc, [1 $\left.1^{\circ} 18^{\prime} \mathrm{N} 11^{\circ} 20^{\prime} \mathrm{E}\right]$, VII1945, Guinea 351, 352 (MA 514644). Río Muni: Orla de montes isla, fotografía (Parmentier \& Nguema, 2001: 215).

9. P. punctatus L'Hér., Stirp. Nov. 4: 87, tab. 42 (1785)

Tipo: "Habitat in Abyssinia. Bruce".

Iconografía: L'Hér., Stirp. Nov. 4: tab. 42 (1785) [Fig. 20].

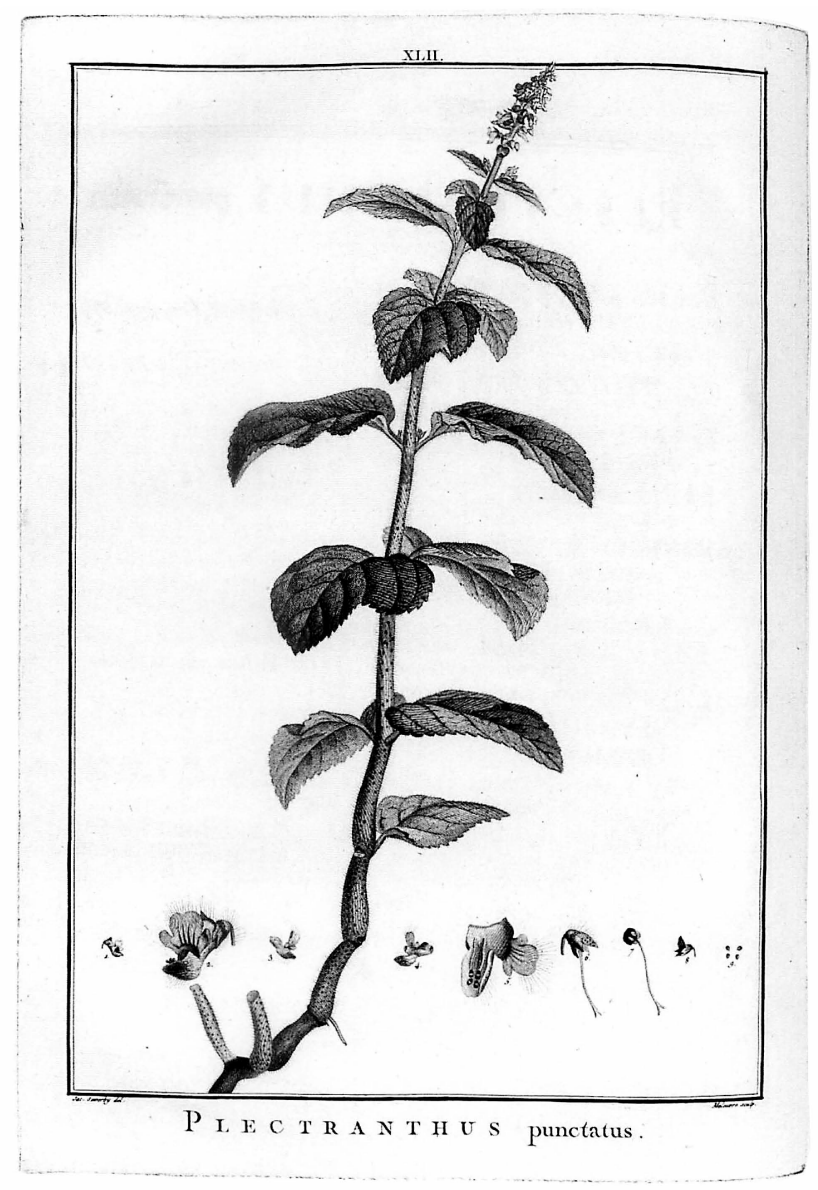

Fig. 20. Plectranthus punctatus, icono de la obra de L'Héritier, 1785.
Planta 0,15-0,5 m, herbácea, postrada, ascendente, con tallos pelosos, lanosos, sobre todo arriba. Hojas $1,2-4 \times 1-2,8 \mathrm{~cm}$, cortamente pecioladas o sentadas, ovadas, dentadas, pelosas, con frecuencia maculadas. Inflorescencia en verticilastros, con hasta 8 flores pediceladas cada uno. Cáliz 5,5-7 mm, pelosos, con diente superior más ancho, todos de la misma longitud, curvados hacia arriba. Corola 7-8 mm, con tubo giboso, labio superior c. $3 \mathrm{~mm}$ y lóbulo inferior c. 5 $\mathrm{mm}$, color azul claro, azul morado o lila. $2 n=28$.

Praderas con arbustos, junto al borde de la pista; 2400-2620 m. Bioko, en el pico Basilé (Fig. 15). Según Morton (1963: 460) se encuentra también en Camerún.

\section{Material estudiado}

Bioko Norte: Pico Santa Isabel, 1-III-1947, Guinea 2649-2652 (MA 514647). Regreso del pico Santa Isabel, III-1947, Guinea 2930 (MA 514605). Carretera del pico Basilé, km 15-16, 32NMK7700, pradera con arbolillos y arbustos, 5-X-1988, Carvalho 3640 (MA 514504). Herbácea postrada ascendente. Flores color lila. Esparcida en pequeñas colonias. Bioko Sur: Subida al pico Basilé, 32NMJ7497, 2620 m, malezas junto a la pista, 10-VII-1986, Fernández Casas 10327 \& al. (MA 514531, MA 533852). Flores azules. Aspecto vegetativo de Mentha rotundifolia. Carretera del pico Basilé, km 19-20, 32NMJ7497, 2400 m, pradera con arbustos, 7-X-1988, Carvalho 3657 (MA 514516). Herbácea más o menos postrada que forma pequeñas colonias. Flores azul moradas. Carretera del pico Basilé, $\mathrm{km}$ 20,32NMJ7497, $2450 \mathrm{~m}$, pradera con arbustos cubiertos de líquenes, 10-XI-1988, Carvalho 3701 (MA 514514). Herbácea postrada o ascendente que forma pequeñas colonias. Hojas maculadas por el haz. Flores azuladas. Carretera al pico Basilé, km 21, 32NMJ7497, 2600 m, márgenes de la pista, 5-II-1989, Fernández Casas 11217, R. Morales E al. (MA 514621). 0,5 m. Flores de color azul claro. Carretera del pico Basilé, km 20, 32NMJ7497, 2480 m, márgenes de la pista, 5-II-1989, Fernández Casas 11220, R. Morales E al. (MA 514623). 0,5 m. Hojas maculadas. Flores de color azul claro. Summit grassland, VII, Boughey GC 10968 (Morton, 1963: 460, 14.12).

10. P. rotundifolius (Poiret) Sprengel, Syst. Veg., ed. 16, 2: 690 (1825)

Germanea rotundifolia Poiret in Lam., Encycl. 2: 763 (1812)

Solenostemon rotundifolius (Poiret) J.K. Morton, J. Linn. Soc., Bot. 58: 272 (1952)

Coleus dysentericus Baker, Bull. Misc. Inform. Kew: 10 (1894)

P. coppinii Cornu, C. R. Acad. Paris 130: 1268 (1901)

Tipo: "Ins. Mascaren.".

Descripción e iconografía: J. Berhaut (1975). Fl. ill. Sénégal 4: 232-233.

Planta robusta, perenne, \pm erguida. Hojas 7-12 × 6$7 \mathrm{~cm}$, pecioladas, anchamente ovadas, agudas, con grandes dientes simétricos, redondeados, pelosa en los nervios. Inflorescencia hasta de $30 \mathrm{~cm}$, tirsoide, 
con largos ejes de verticilastros racemosos. Cáliz 5-6 $\mathrm{mm}$, acrescente, con dientes laterales redondeados. Corola hasta $7 \mathrm{~mm}$, color azulado. $2 n=$ c. 84 .

Planta cultivada. Bioko. Exell (1973: 387-388, fam. 128) no la cita para Bioko. Según Morton (1963: 463) vive también en Senegal, Costa de Marfil, Ghana y Nigeria.

\section{Material estudiado}

Bioko Norte: Servicio Agronómico de Santa Isabel, 29-XII-1946, Guinea 551, 555 (MA 514645). Santa Isabel, Campo Hausa (Nosti, 1955: 293). Bioko Sur: Basakato del Oeste (Nosti, 1955: 293).

Nombre vulgar: Patata de los hausas

Usos: Nosti (1955: 292) cita esta planta como Coleus dysentericus Baker. Indica que solamente se cultiva en la isla la var. nigra y que se encuentra en Campo Hausa (Santa Isabel) y en Basakato del Oeste. Los tubérculos alimenticios pueden sustituir a la patata, y da mayor cosecha en zonas bajas, hasta los $500 \mathrm{~m}$.

\section{Pycnostachys Hooker}

Consta de unas 40 especies africanas y de Madagascar (Paton in Harley \& al., 2004: 267).

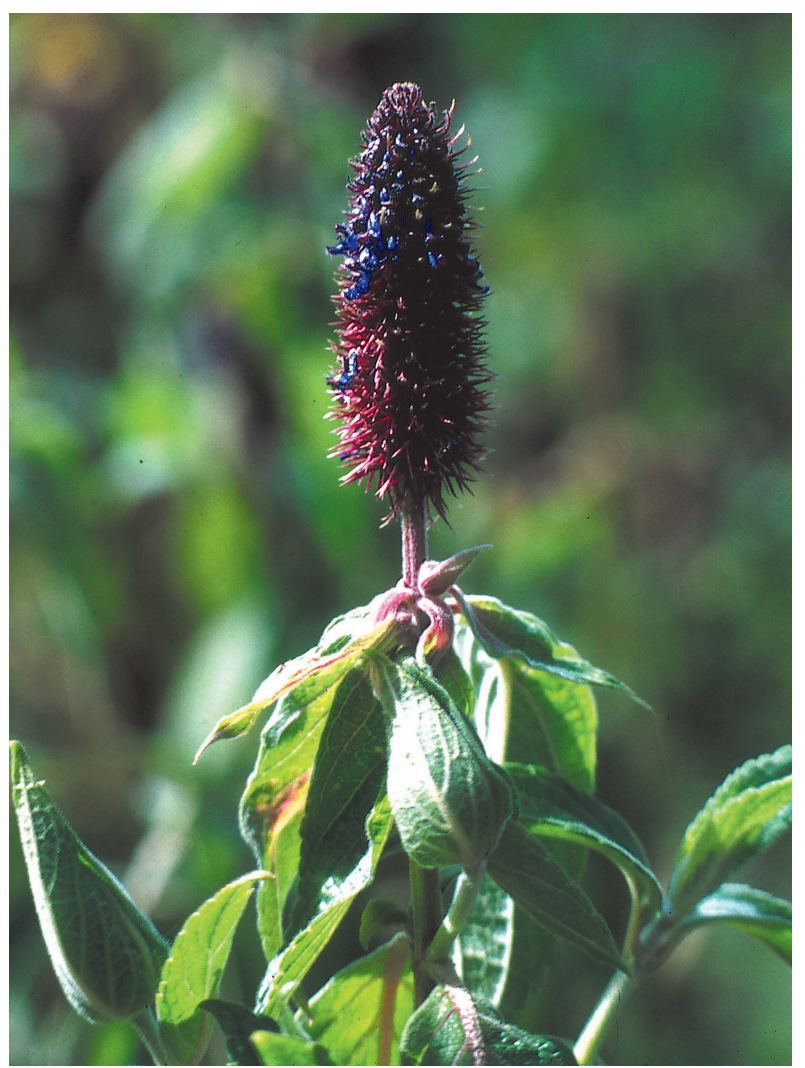

Fig. 21. Pycnostachys meyeri, subida al pico Basilé, 5-II-1989, R. Morales.

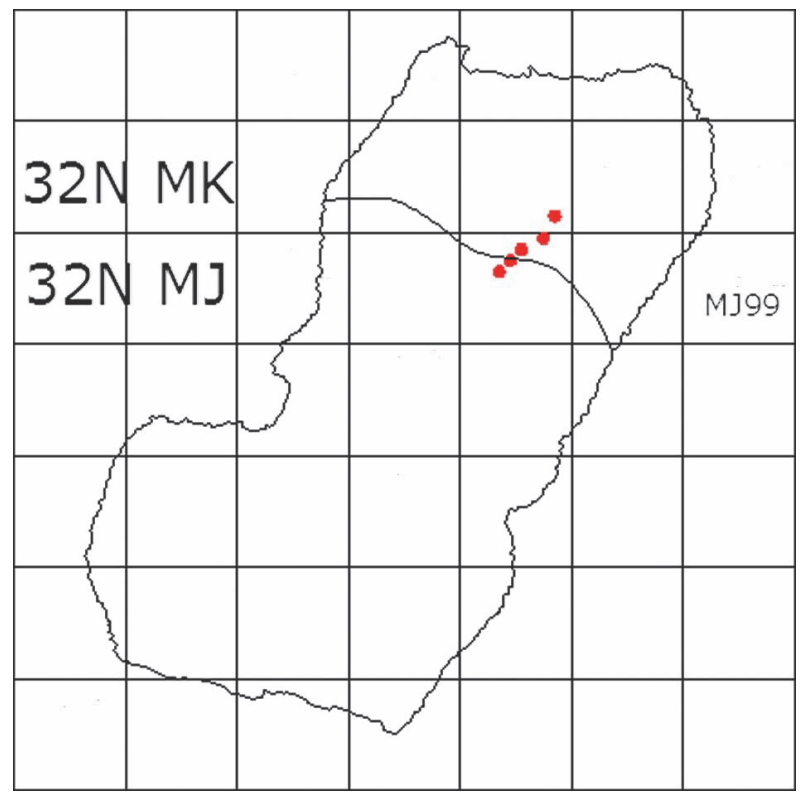

Fig. 22. Distribución en Bioko de Pycnostachys meyeri.

1. P. meyeri Gürke in Engler, Über die Hochsgebirgsflora des tropischen Afrika: 362 (1892)

P. volkensii Gürke in Engler, Pflanzenwelt Ost-Afrika C: 344 (1895)

Tipo: "Kilimandscharo, im Urwald am Ruabach 1900-2300 m (Dr. Hans Meyer n. 279)".

Iconografía: E. Guinea (1949). En el país de los bubis: 240 fig. 89. Fig. 21.

Planta 1-1,5 m, herbácea arbustiva, muy ramifica$\mathrm{da}$, a veces en macollas, de olor penetrante, con tallos afelpados. Hojas 4-13,5 × 1,5-3 cm, pecioladas, lanceoladas, aserradas, con dientes dirigidos hacia arriba, al menos las jóvenes densamente pelosas. Inflorescencia 3-7 × 2-2,5 cm, espiciforme. Cáliz coriáceo, con dientes espinosos de c. $5 \mathrm{~mm}$. Corola c. $9 \mathrm{~mm}$, con lóbulo inferior sobresaliente, cóncavo, color azul, azul púrpura, \pm fuerte. $2 n=34$.

Praderas con arbustos, o taludes de carretera; 21002950 m. Bioko, en la zona del pico Basilé (Fig. 22). Según Morton (1963: 458) vive en Guinea, Nigeria, Camerún y también en el Congo y E de África.

Aunque Engler (1.c.: 362) considera que las poblaciones de Fernando Poo corresponden a Pycnostachys abyssinica Fresen., Flora 21(2): 608 (1838), y cita la recolección de Mann 280 como testimonio, Bruce (1940: 591), en su magnífica monografía del género, incluye esta misma recolección como $P$. meyeri. 


\section{Material estudiado}

Bioko Norte: Oberhalb der Waldgrenze, XI-1911, Mildbraed 7159 (Mildbraed, 1922: 191). Carretera del pico Basilé, 32NMJ7799, 2000 m, márgenes de la pista, 9-VII-1986, Fernández Casas 10300 E al. (MA 514529). 1,4 m. Flores azules. Olor penetrante. Carretera al pico Basilé, km 17-18, 32NMK7801, 1750 m, taludes de carretera, 8-X-1986, Carvalho 2541 (MA 412176). Erecta de 1-1,2 m. Flores de color azul, terminales. Forma pequeñas macollas densas. Carretera al pico Basilé, km 17-18, 32NMJ7598, 2200 m, pradera con arbustos, 1-XI-1988, Carvalho 3670 (MA 514515). Herbácea de 1-1,3 m, muy ramificada. Flores de color azul púrpura. Bioko Sur: Pico Santa Isabel, [32NMJ7497], 2800 m, 12-14-V-1939, Lope del Val (Guinea 631) (MA 714072). Pico de Santa Isabel, [32NMJ7396], \pm 2950 m, 1-III-1947, Guinea 2670 (MA 255540), Guinea 2684. Cumbre del pico Basilé, 32NMJ7497, 2680 m, márgenes de la pista, 3-VII-1986, Fernández Casas 10171 E al. (MA 514530). Arbusto de 1,5 m. Flores de color azul muy fuerte. Carretera al pico Basilé, km 21, 32NMJ7497, 2600 m, márgenes de la pista, 5-II-1989, Fernández Casas 11216, R. Morales E al. (MA 514620). 1,5 m. Flores de color azul fuerte. Clarence Peak, [32NMJ7598], $7000 \mathrm{ft}$ [2100 m], Mann 280 (Morton, 1963: 458, 13.2). XII, Boughey GC 12685 (Morton, 1963: 458, 13.2).

\section{Stachys L.}

Consta de unas 300 especies que viven en regiones templadas y en las montañas tropicales (Krestovskaja in Harley \& al., 2004: 223).

1. Tallos con acúleos, glabros; cáliz 4-5 mm; corola 5-6 mm . 1. S. aculeolata

1. Tallos con acúleos muy pequeños, pelosos; cáliz 5-5,5 mm; corola 10-12 mm....

2. S. pseudohumifusa

1. S. aculeolata Hooker fil., J. Proc. Linn. Soc., Bot. 6: 18 (1861)

Tipo: "Hab. Clarence Peak, alt. 9000 ped. (fl. Dec.)". Holótipo: Fernando Poo, Clarence Peak, Mann 319 (K).

Descripción e iconografía: Kew Bull. 51(3): 439, 441 (1996).

Planta 0,8-1,2 m, herbácea, postrada, ascendente con tallos glabros, con acúleos. Hojas 2,5-6 $\times$ 1,5-3 cm, con largos pecíolos, cordadas en la base, ovadas, agudas, dentadas, con dientes redondeados, dispersamente pelosas, con pelos plateados. Inflorescencia en verticilastros con 2-8 flores, con brácteas como las hojas, pero más pequeñas. Cáliz $4-5 \mathrm{~mm}$, peloso, con 5 dientes c. $1 \mathrm{~mm}$. Corola 5-6 mm, con labio inferior sobresaliente, color rosado, lila pálido o blanco. $2 n=52$.

Bosques primario o secundario con árboles bajos, en taludes de carretera, 1270-2700 m. Bioko (Fig. 23). Guinea (1949: 259) la cita para Bioko. Según Morton (1963: 469) vive en las montañas de Camerún, Congo, Etiopía, Uganda y Kenia.

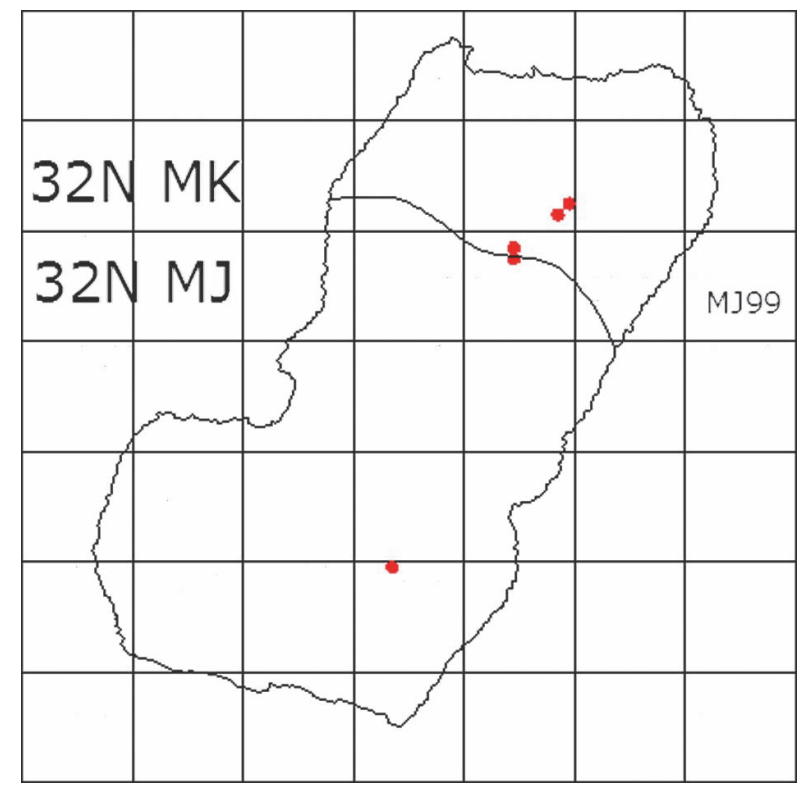

Fig. 23. Distribución en Bioko de Stachys aculeolata.

Según Harvey (1996: 440), correspondería a la var. aculeolata, que vive además en Tanzania, Ruanda, Burundi y Nigeria.

\section{Material estudiado}

Bioko Norte: 1400-1500 m, VIII-1911, Mildbraed 6315 (Mildbraed, 1922: 191). Carretera al pico Basilé, km 11, 32NMK7902, 1470 m, taludes de carretera, 9-VIII-1986, Carvalho 2265 (MA 514518). 1-1,2 m. Flores rosadas. Forma pequeñas colonias dispersas. Carretera al pico Basilé, km 13-14, 32NMK7801, bosque primario con Ficus, Trema, etc., 10-III-1989, Carvalho 3793 (MA 514517). Herbácea postrada o ascendente. Flores lila pálido. Relativamente abundante. Bioko Sur: Clarence Peak, [32NMJ7497], $9000 \mathrm{ft}$ [2700 m], X, Mann 319 (K) (Morton, 1963: 469, 26.2). Luba-Riaba, pastos de APROCAGE, 32NMJ6369, 1270 m, bosque secundario con árboles de bajo porte, 15-XI-1989, Carvalho 4182 (MA 514524). Herbácea de $1 \mathrm{~m}$. Flores blancas. Bioko: Monod 68 (Morton, 1963: 469, 26.2).

2. S. pseudohumifusa Sebsebe, Kew Bull. 48(1): 117 (1993) [ver 51(3): 451 (1996)]

Tipo: "Tanzania (T7), Iringa District". Holótipo: Tanzania, Iringa Distr., Bidgood, Mwasumbi \& Vollesen 839, K; isótipos DSM, EA, WAG.

Descripción e iconografía: Kew Bull. 51(3): 449-450 (1996).

Planta 0,3-0,6 m, herbácea, postrada o ascendente, con tallos pelosos y con acúleos muy pequeños. Hojas 1-3 $\times 1-1,7 \mathrm{~cm}$, pecioladas, cordadas en la base, ovadas o triangulares, de dentadas a lobuladas, glabras o con pelos dispersos. Inflorescencia en verticilastros con 2-4 flores. Cáliz 5-5,5 mm, pedicelado, peloso, con 5 dientes agudos. Corola 10-12 mm, con lóbulo 
central del labio inferior de 4-6 mm, color blanco con pintas moradas por dentro.

Pradera con arbustos; 2500-2800 m. Bioko, en el Pico Basilé (Fig. 10). Exell (1973: 387, fam. 128) no la cita para Bioko. Sebsebe Demissew \& Harley (1992: 153) la citan para Camerún.

Según Harvey (1996: 451), correspondería a la subsp. saxeri Y.B. Harvey, que se encuentra además en Nigeria.

\section{Material estudiado}

Bioko Norte: Regreso del pico Santa Isabel, $\pm 2500 \mathrm{~m}, 1$-III1947, Guinea 2705 (MA 168519), Guinea 2899 (MA 511334). Bioko Sur: Carretera del pico Basilé, junto a la Virgen de la Isla, 32NMJ7396, $2800 \mathrm{~m}$, pradera con arbustos, 18-V-1989, Carvalho 3968 (MA 525874). Herbácea postrada o ascendente. Flores blancas con pintas moradas por dentro. Muy rara.

\section{Encuadre taxonómico y consideraciones biogeográficas}

Según Harley \& al. (2004), los géneros estudiados pertenecen a las siguientes subfamilias, tribus y subtribus. Se indica el número de género que les corresponde en dicha obra.

VII. Lamioideae:

66. Achyrospermum

100. Stachys

119. Leucas

120. Leonotis

VIII. Nepetoideae

2. Mentheae

b. Menthinae:

146. Micromeria

150. Calamintha (incluido en Clinopodium)

c. Nepetinae:

$$
\text { 178. Nepeta }
$$

3. Ocimeae

b. Hanceolinae:

193. Isodon

c. Hyptidinae:

200. Hyptis

d. Ociminae:

204. Ocimum

209. Hoslundia

215. Platostoma

e. Plectranthinae

219. Plectranthus

226. Pycnostachys

Desde el punto de vista biogeográfico y a la vista de la Tabla 1 se observa que de las 28 especies de labiadas que viven en Guinea Ecuatorial, 26 se encuentran en Bioko, 5 en Annobón y solamente 10 en la región con- tinental. Hyptis suaveolens y Plectranthus inselbergi son especies que aparecen solo en Río Muni, y no viven en las islas. La primera es introducida de origen americano. La segunda es exclusiva de los montes isla de Río Muni y zonas proximas de Gabón (Pollard \& al., 2006). Hay 16 especies que viven en Bioko, y que no se encuentran en Río Muni ni en Annobón. No hay ninguna exclusiva de Annobón. Y 3 especies viven en las tres regiones.

De todas estas especies, las ciertamente introducidas son Hyptis suaveolens, Ocimum americanum, $O$. basilicum y Plectranthus rotundifolius. Sin embargo, Leonotis nepetifolia, Leucas martinicensis y Ocimum gratissimum probablemente lo sean también, pero en la actualidad se encuentran suficientemente naturalizadas. Estas tres especies son pantropicales. Si no se consideran las especies alóctonas, serían 20 las especies de labiadas que viven en Bioko y 9 en Río Muni, la región continental.

La mayor riqueza florística en cuanto a especies de labiadas se encuentra en la isla de Bioko, debido sin duda a su altitud. El pico Basilé, de origen volcánico, que alcanza los $3000 \mathrm{~m}$, tiene en su piso superior de pradera una flora de sumo interés desde el punto de vista de su composición, ya que aparecen elementos al menos a nivel genérico de las regiones templadas de Eurasia: Calamintha pseudosimensis, Micromeria punctata, Nepeta robusta, Stachys aculeolata, Stachys pseudobumifusa, así como géneros de otras familias, como Adenocarpus mannii, Alchemilla cryptantha, Veronica mannii. Como es sabido, la isla sería la continuación de la cordillera emergente que nace en el pico Camerún y que da después lugar a dicha isla de Bioko, y más hacia el SW a Santo Tomé, Principe y Annobón. Las 5 especies de labiadas anteriormente indicadas viven casi exclusivamente en la zona del pico Basilé, salvo Stachys aculeolata que también se encuentra en la zona montana del S de la isla. Además Pycnostachys meyeri es planta de las montañas africanas, y en Guinea Ecuatorial se encuentra también únicamente en la zona del pico Basilé.

A nivel genérico existen elementos exclusivamente africanos, como Hoslundia y Pycnostachys. Hay que resaltar el género Hoslundia como monoespecífico y exclusivo africano. Hoslundia opposita es una planta muy especializada; se trata de un bejuco que presenta cáliz engordado cuando maduro y de color amarillo, atrayente para ser comido y dispersado por aves. Se encuentra en todo el territorio, parte continental e islas. Pycnostachys consta de unas 40 especies africanas y de Madagascar. Leonotis es un género africano que consta de 10 especies, pero la especie L. nepetifolia vive en todas las regiones tropicales del mundo. Por ello no se sabe si es planta alóctona en la región estudiada. 
Tabla 2. Relación de especies presentes (43 especies) en Camerún (37 especies) (Morton, 1963; Cheek \& al., 2004), Gabón (11) (Sosef, 2006) y Sao Tomé y Príncipe (Exell, 1944, 1956, 1973), no encontradas en el territorio. Cinco especies son comunes a ambos territorios; además aparecen nueve nuevos géneros autóctonos que no están en el territorio estudiado. C, Camerún; G, Gabón; S, Sao Tomé.

\begin{tabular}{|l|c|}
\hline Especie & Origen \\
\hline Achyrospermum africanum Hooker fil. ex Baker & C \\
\hline Achyrospermum ciliatum Gürke & G \\
\hline Achyrospermum dasytrichum Perkins & C \\
\hline Achyrospermum erythrobotrys Perkins & C \\
\hline Achyrospermum schlechteri Gürke & C \\
\hline Achyrospermum tisserantii Letouzey & G \\
\hline Aeollanthus repens Oliv. & C \\
\hline Aeollanthus heliotropioides Oliv. & C \\
\hline Becium obovatum (E. Mey.) M.E. Br. & C \\
\hline Englerastrum gracillimum Th. C.E. Fries & C \\
\hline Englerastrum schweinfurthii Birquet & G \\
\hline $\begin{array}{l}\text { Haumaniastrum alboviride (Hutch.) } \\
\text { Duvign. \& Plancke }\end{array}$ & C \\
\hline Haumaniastrum buettneri (Gürke) J.K. Morton & C \\
\hline Haumaniastrum caeruleum (Oliv.) J.K. Morton & C \\
\hline Hemizygia bracteosa (Bentham) Briquet & C \\
\hline Hemizygia welwitschii (Rolfe) M. Ashby & C \\
\hline Hyptis atrorubens Poit. & G \\
\hline Hyptis pectinata (L.) Poit. & C \\
\hline Hyptis spicigera Lam. & C \\
\hline Leocus africanus (Baker ex S.C. Elliot) J.K. Morton & C \\
\hline Leocus caillei (A. Chev. ex Hutch. \& Dalz.) & C \\
\hline Leucas oligocephala Hooker fil. & C \\
\hline
\end{tabular}

Achyrospermum, con unas 25 especies, se extiende por las islas del océano Índico hasta la India, Nepal, Sur de China, Tailandia, Indonesia y Filipinas. Isodon se extiende por gran parte del $\mathrm{S}$ y E de Asia y consta de unas 100 especies; de ellas una fue descrita como género nuevo Homalocheilos, y llega al continente africano en su límite occidental de área. Leucas consta también de unas 100 especies, que se extienden desde África tropical y del sur hasta el SE de Asia y Japón; la especie Leucas deflexa es exclusiva del W de África, y se extiende desde Ghana hasta Angola. Platostoma es un género tropical que consta de unas 45 especies que viven en África y Asia tropical, y algunas de ellas en Australia.

Como ya se ha dicho más arriba, Calamintha pseudosimensis, Micromeria punctata, Nepeta robusta,

\begin{tabular}{|c|c|}
\hline Especie & Origen \\
\hline Neohyptis paniculata (Baker) J.K. Morton & $C, G$ \\
\hline Ocimum lamiifolium Hochst. ex Bentham & $C, G$ \\
\hline Platostoma denticulatum Robyns & $C, G$ \\
\hline Platostoma gabonense A.J. Paton & G \\
\hline Platostoma rotundifolium (Briquet) A.J. Paton & $\mathrm{C}$ \\
\hline Plectranthus cyaneus Gürke & C \\
\hline Plectranthus decumbens Hooker fil. & C \\
\hline Plectranthus dissitiflorus (Gürke) J.K. Morton & C \\
\hline Plectranthus esculentus N.E. Br. & C \\
\hline Plectranthus insignis Hooker fil. & C \\
\hline Plectranthus kamerunensis Gürke & C \\
\hline Plectranthus luteus Gürke & $C, G$ \\
\hline $\begin{array}{l}\text { Plectranthus tenuicaulis (Hooker fil.) } \\
\text { J.K. Morton }\end{array}$ & C \\
\hline Pycnostachys batesii Baker & C \\
\hline Pycnostachys eminii Gürke & C \\
\hline Pycnostachys pallide-caerulea Perkins & C \\
\hline Pycnostachys reticulata (E. Meyer) Bentham & C \\
\hline Salvia coccinea Buc'hoz ex Etlinger & S \\
\hline Scutellaria violascens Gürke & C \\
\hline Solenostemon graniticola A. Chev. & G \\
\hline $\begin{array}{l}\text { Solenostemon latifolius (Hochst. ex Benth.) } \\
\text { J.K. Morton }\end{array}$ & $C, G$ \\
\hline Stachys arvensis (L.) L. & S \\
\hline Tinnea aethiopica Kotschy \& Peyr. & $C$ \\
\hline
\end{tabular}

Stachys aculeolata y S. pseudobumifusa son 5 especies correspondientes a 4 géneros que se refugian en las montañas africanas, y que son característicos de regiones templadas y frías.

Hyptis es un género que se compone de unas 280 especies, todas americanas excepto algunas que viven en los trópicos del Viejo Mundo, algunas de ellas introducidas. Hyptis lanceolata es muy probable que sea nativa en el área africana donde vive, sobre todo en África occidental.

El género Ocimum consta de unas 65 especies que viven en los trópicos de todo el mundo y es género en su origen exclusivamente tropical. Las especies de Ocimum son probablemente asilvestradas de origen cultivado y algunas procedentes de Asia. 
Se podría decir que el género Plectranthus es uno de los más genuinos tropicales dentro de la familia. Consta de unas 300 especies, que viven en los trópicos del Viejo Mundo. En Guinea Ecuatorial llega a su límite de área y en ella solamente viven 9 especies autóctonas, 8 de ellas en la isla y 5 en el continente. Una de ellas, la más común, también se encuentra en Annobón (P. monostachyus). Es el único género de labiadas que ha producido endemismos en la región. Así $P$. cataractarum es una especie reofítica de la isla de Bioko y el monte Camerún (Pollard \& Paton, 2001); $P$. punctatus vive también exclusivamente en el monte Camerún y el pico Basilé; P. inselbergi, como ya se ha dicho más arriba, es exclusiva de los montes isla de Río Muni y zonas próximas de Gabón, P. decurrens es endemismo del golfo de Guinea (Nigeria, Camerún, Gabón, Río Muni y Bioko); y P. epilitbicus y P. monostachyus son también exclusivas del W de África.

En los países vecinos, en Camerún se encuentran 9 géneros y 37 especies autóctonos que no aparecen en Guinea Ecuatorial; y 2 géneros y 11 especies en Gabón en los que ocurre lo mismo. De ello se concluye que, sobre todo el continente pero también la isla, tienen una flora empobrecida con respecto a sus países vecinos, sobre todo Camerún. Pese a todo, desde el punto de vista biogeográfico resulta mucho más interesante la isla de Bioko que la región continental, Río Muni.

\section{Agradecimientos}

A Alfredo Barra, por la elaboración de los mapas de distribución en soporte informático; a José Luis Fernández Alonso, por su ayuda en el género Hyptis, y a Antonio Martín Ciudad, Adela Bornia, Fátima Cabrera y Ana Meco, por su ayuda técnica. Este trabajo ha sido realizado dentro del proyecto Flora de Guinea Ecuatorial (CGL2009-07405/BOS).

\section{Referencias bibliográficas}

Aedo, C., Morales, R., Tellería, M.T. \& Velayos, M. (eds.). 2001. Botánica y botánicos en Guinea Ecuatorial. Real Jardín Botánico, CSIC \& AECI. Madrid.

Bruce, E.A. 1940. LX.- The genus Pycnostachys. Kew Bulletin of miscellaneous information 1939(10): 563 - 593 [463-493].

Cheek, M., Pollard, B.J., Darbyshire, I., Onana, J.M. \& Wild, C. 2004. The plants of Kupe, Mwanenguba and the Bakossi Mountains, Cameroon. A conservation checklist. Royal Botanic Gardens Kew.

Exell, A.W. 1944. Catalogue of the vascular plants of S. Tomé (with Principe and Annobon). British Museum. London.

Exell, A.W. 1956. Supplement to the catalogue of the vascularplants of S. Tomé (with Principe and Annobon). British Museum. London.

Exell, A.W. 1973. Angiosperms of the islands of the Gulf of Guinea (Fernando Poo, Príncipe, S. Tomé and Annobon). Bulletin of the British Museum. (Natural History) Botany 4(8): 325-411.

Gómez, E. \& Merino, L. 1990. Plantas medicinales de Guinea Ecuatorial. Centro Cultural Hispano-Guineano Ediciones.

Gómez, E. \& Merino, L. 2001. Usos de las plantas medicinales en Guinea Ecuatorial. In: Aedo, C., Morales, R., Tellería, M.T. \&
Velayos, M. (eds.), Botánica y botánicos en Guinea Ecuatorial: 91-131. Madrid.

Guinea, E. 1946. Ensayo geobotánico de la Guinea Continental Española. Dirección General de Marruecos y Colonias. Madrid.

Guinea, E. 1949. En el país de los Bubis. Instituto de Estudios Africanos. Madrid.

Li, H. 1988. Taxonomic review of Isodon (Labiatae). Journal of the Arnold Arboretum 69(4): 289-400.

Harley, R.M., Atkins, S., Budantsev, A.L., Cantino, P.D., Conn, B.J., Grayer, R., Harley, M.M., De Kok, R., Krestovskaja, T., Morales, R., Paton, A.J., Ryding, O. \& Upson, T. 2004. Labiatae. In: Kadereit, J.W. (ed.)\& Kubitzki, K. (ed. in chief), The Families and Genera of Vascular Plants VII. Flowering Plants. Dicotyledons: Lamiales (except Acanthaceae including Avicenniaceae): 167-275. Springer. Berlin.

Harvey, Y.B. 1996. The Stachys aculeolata / aethiopica complex in tropical Africa. Kew Bulletin 51(3): 433-454.

Hooker, J.D. 1862. On the vegetation of the Clarence Peak, Fernando Poo; with descriptions of the plants collected by Mr. Gustav Mann on the higher parts of this mountain. Journal Proc. of the Linnean Society, Botany 6: 1-23.

Mildbraed, J. 1922. Wissenschaftliche Ergebnisse der zweiten deutschen Zentral-Afrika-Expedition 1910-1911. Band II: Botanik. Verlag von Klinkhardt \& Biermann. Leipzig.

Morales, R. 1990. Micromeria punctata Bentham, novedad para Guinea Ecuatorial, en la isla de Bioco. Anales del Jardín Botánico de Madrid 48(1): 90-91.

Morales, R. 1993. Lamiaceae Guineae Aequatoriales nonnullae. Fontqueria 36: 278-291.

Morales, R. 1994. Lamiaceae Guineae Aequatoriales nonnullae, II. Fontqueria 39: 13-16.

Morales, R. 2001. Utilización de recursos y agronomía en Guinea Ecuatorial. Aspectos históricos. In: Aedo, C., Morales, R., Tellería, M.T. \& Velayos, M. (eds.), Botánica y botánicos en Guinea Ecuatorial: 51-75. Madrid.

Morton, J.K. 1962. Cytogenetic studies on the West African Labiatae. Journal of the Linnean Society, Botany 58: 231-283.

Morton, J.K. 1963. 162. Labiatae. In: Hutchinson, J., Dalziel, M. \& Hepper, F.N. (eds.), Flora of West Tropical Africa 2, ed. 2: 450-473.

Nosti Nava, J. 1955. La agricultura en Guinea Ecuatorial. I.- La planta. Dirección General de Marruecos y Colonias. Madrid.

Parmentier, I. \& Nguema, N. 2001. La vegetación de los inselbergs de Río Muni. In: Aedo, C., Morales, R., Tellería, M.T. \& Velayos, M. (eds.), Botánica y botánicos en Guinea Ecuatorial: 201-230. Madrid.

Paton, A. 1992. A synopsis of Ocimum L. (Labiatae) in Africa. Kew Bulletin 47(3): 403-435.

Pollard, B.J. 2005. Two new names in African Plectranthus (Labiatae). Kew Bulletin 60(1): 145-147.

Pollard, B.J. \& Paton, A. 2001. A new rheophytic species of Plectranthus L'Hér. (Labiatae) from the Gulf of Guinea. Kew Bulletin 56: 975-982.

Pollard, B. J., Parmentier, I. \& Paton, A. 2006. Plectranthus inselbergi (Lamiaceae) a new species from Equatorial Guinea (Rio Muni) and Gabon, with notes on other Central and West African species of Plectranthus. Kew Bulletin 61: 225-230.

Ryding, O. 2007. Revision of the Micromeria (Labiatae) in tropical to southern Africa and on the Arabian Peninsula. Botanical Journal of the Linnean Society 155(3): 427-446.

Sebsebe Demissew \& Harley, M.M. 1992. Trichome, seed surface and pollen characters in Stachys (Lamioideae; Labiatae) in Tropical Africa. In: Harley, R.M. \& Reynolds, T. (eds.), Advances in Labiate Science: 149-166. Royal Botanic Gardens, Kew.

Seybold, S. 1988. Die Arten der Gattung Satureja L. (Labiatae) in Äthiopien. Stuttgarter Beiträge zur Naturkunde, Serie A, Biologie, 421: 1-38.

Sosef, M.S.M. \& al. 2006. Check-list des plantes vasculaires du Gabon. Scripta Botanica Belgica 35. 


\section{Índice taxonómico}

Se indican el número de género y especie y si aparecen al comienzo del catálogo (Obs.). No se incluyen las especies de la Tabla 2.

\author{
Achyrospermum oblongifolium Baker, 1.1 \\ Aeolanthus pubescens Benth., Obs. \\ Ballota suaveolens L., 4.2 \\ Calamintha pseudosimensis (Brenan) R. Morales, 2.1 \\ C. simensis Bentham, 2.1 \\ Clinopodium martinicense Jacq., 7.2 \\ Coleus assurgens Baker, 12.1 \\ C. carnosus A. Chev., 12.4 \\ C. carnosus Hassk., 12.4 \\ C. dazo A. Cev. \& Perrot., 12 \\ C. decurrens Gürke, 12.3 \\ C. dysentericus Baker, 12.10 \\ C. elatus Baker, 12.3 \\ C. mannii Hooker fil., 12.8 \\ C. repens Gürke, 12.4 \\ C. verschaffeltti Lem., 12 \\ Germanea rotundifolia Poiret in Lamarck, 12.10 \\ Homalocheilos, 5 \\ H. ramosissimus (Hooker fil.) J.K. Morton, 5.1 \\ Hoslundia opposita Vahl, 3.1 \\ Hyptis brevipes sensu, ver 4.1 \\ H. lanceolata Poiret in Lam., 4.1 \\ H. suaveolens (L.) Poit., 4.2 \\ Isodon ramosissimus (Hooker fil.) Codd, 5.1 \\ Leonotis nepetifolia (L.) R. Br. in W.T. Aiton, 6.1 \\ Leucas deflexa Hooker fil., 7.1 \\ L. martinicensis (Jacq.) R. Br. in W.T. Aiton, 7.2 \\ Mentha sativa L., Obs. \\ M. spicata L., Obs. \\ Micromeria biflora var. punctata (Bentham) Fiori, 8.1 \\ M. punctata Bentham, 8.1 \\ Nepeta robusta Hooker fil., 9.1 \\ Ocimum americanum L., 10.1 \\ O. basilicum L., 10.2 \\ O. canum Sims, 10.1 \\ O. gratissimum L., 10.3 \\ O. monostachyum P. Beauv., 12.7 \\ O. viride Willd., 10.3 \\ Phlomis nepetifolia L., 6.1 \\ Platostoma africanum P. Beauv., 11.1
}

Plectranthus assurgens (Baker) J.K. Morton, 12.1

P. cataractarum B.J. Pollard in Pollard \& Paton, 12.2

P. coppinii Cornu, 12.10

P. cymosus Baker, 12.8

P. decumbens Hooker fil., 12.2

P. decurrens (Gürke) J.K. Morton, 12.3

P. epilithicus B.J. Pollard, 12.4

P. esculentus N.E. Brown, 12

P. glandulosus Hooker fil., 12.5

P. bylophilus Gürke, 12.5

P. inselbergi B.J. Pollard \& A.J. Paton, 12.6

P. insignis Hooker fil., 12

P. mannii Baker, ver 12.8

P. monostachyus (P. Beauv.) B.J. Pollard in Pollard \& Paton subsp. monostachyus, 12.7

P. occidentalis B.J. Pollard, 12.8

P. punctatus L.'Héritier, 12.9

$P$. repens Wallich, ver 12.4

P. ramosissimus Hooker fil., 5.1

P. rotundifolius (Poiret) Sprengel, 12.10

P. scutellarioides (L.) R. Br., 12

Pycnostachys abyssinica Fresen., 13.1

P. meyeri Gürke in Engler, 13.1

P. volkensii Gürke, 13.1

Salvia coccinea Buchoz, Obs.

Satureja pseudosimensis Brenan, 2.1

S. punctata (Bentham) Briquet in Engler \& Prantl, 8.1

S. robusta (Hooker fil.) Brenan, 9.1

S. simensis (Bentham) Briquet, 2.1

Solenostemon, 12

S. cymosus Baker, 12.8

S. decumbens (Hooker fil.) Baker, 12.2

S. decumbens sensu Morales, ver 12.2

S. mannii (Hooker fil.) Baker, 12.8

S. monostachyus (P. Beauv.) Briquet in Engler \& Prantl subsp. monostachyus, 12.7

S. ocymoides Schum. \& Thonn., 12.7

S. repens (Gürke) J.K. Morton, 12.4

S. rotundifolius (Poiret) J.K. Morton, 12.10

Stachys aculeolata Hooker fil., 14.1

S. pseudohumifusa Sebsebe, 14.2

Tinnea barteri Gürke, Obs.
Editor asociado: M. Velayos

Recibido: 20-V-2011

Aceptado: 19-IX-2011 